Check for updates

Cite this: Mater. Adv., 2021, 2,7820

Received 17th August 2021 Accepted 31st October 2021

DOI: 10.1039/d1ma00733e

rsc.li/materials-advances

\section{Surface engineering of biodegradable implants: emerging trends in bioactive ceramic coatings and mechanical treatments}

\begin{abstract}
Sagar Nilawar, ${ }^{a}$ Mohammad Uddin*b and Kaushik Chatterjee (DD *a
Biodegradable polymers, metals, and ceramics have emerged as promising alternatives to prepare degradable implants in recent years, which are better alternatives to conventional non-degradable implants to treat a broad range of disorders. Surface engineering strategies are widely applied for enhancing their performance, including orthopedic, cardiovascular, and craniofacial devices, among many others. Bioactive ceramic coatings on degradable biomedical implants can enhance bio-integration and augment healing while tailoring the degradation rate of the device. Bioactive ceramics form a chemical bond with the surrounding tissue, thus helping in the integration process of the implanted polymer or metal device. Several coatings also impart antibacterial activity to minimize infections. Additionally, mechanical surface treatments have emerged as a promising route for surface engineering and have been predominantly used to modify the surface of degradable metallic implants. The mechanical treatment of the surface primarily enhances the bio-corrosion resistance of the implants without compromising biocompatibility. Surface mechanical treatments also improve the biomechanical performance of the implant through surface nanocrystallization. The present review gives an overview of bioactive ceramics commonly used as a coating material for degradable biomedical implants and the effect of bioactive ceramic coating on their biological, corrosion, and mechanical responses. This review also features stateof-the-art mechanical techniques utilized for surface modification of degradable implants. Gaps in the current technology that can be addressed in future research are identified to improve the clinical success of surface-modified degradable implants as they rapidly emerge as the next-generation devices.
\end{abstract}

\section{Introduction}

Biomedical implants are used clinically to replace, support, or enhance non-functional tissues and organs owing to disease, trauma, or congenital defects. In the last few decades, implants have increasingly been developed to assist in the repair and regeneration of tissues as an alternative to transplants, which are scarce and prone to eliciting an adverse immune response. ${ }^{1}$ Biomedical implants can be broadly categorized into two groups, non-degradable and degradable implants based on the biomaterials used. Non-degradable implants are typically used for permanent or long-term applications as replacements. In many applications, these implants will need a second surgery for removal after the completion of the desired healing response to minimize undesired effects and are prone to

\footnotetext{
${ }^{a}$ Department of Materials Engineering, Indian Institute of Science, C. V. Raman Avenue, Bangalore, 560012, India. E-mail: kchatterjee@iisc.ac.in; Tel: $+91-80-22933408$

${ }^{b}$ UniSA STEM, University of South Australia, Mawson Lakes, SA 5095, Australia. E-mail: mohammad.uddin@unisa.edu.au; Tel: +61-8-830-23097
}

infections. In contrast, degradable implants are attractive for short-term applications to provide an appropriate response to the healing site. These implants are designed to degrade and would not need a second surgery. The degradable implant can be fabricated using various degradable materials, including polymers, metals and their alloys, and ceramics. ${ }^{2}$ Degradable polymers include naturally sourced polymers such as chitosan, ${ }^{3,4}$ collagen, ${ }^{5}$ and silk fibroin, ${ }^{6}$ and several synthetic polymers, including polyesters (such as poly(lactic acid) (PLA), ${ }^{7-9}$ polycaprolactone (PCL) ${ }^{10,11}$ ), polyanhydrides, ${ }^{12}$ and polyorthoesters, ${ }^{13}$ among others. Metals such as $\mathrm{Mg}^{14,15}$ $\mathrm{Zn},{ }^{16,17}$ and $\mathrm{Fe}^{18}$ and their alloys are the most widely studied degradable metallic biomaterials. Bioactive glasses ${ }^{19}$ and calcium phosphates $^{20}$ are among the most commonly studied bioresorbable ceramics. Many comprehensive reviews are available in the literature on each of these classes of degradable materials. ${ }^{21-23}$

Bioceramics are often classified into bio-inert, bioactive, and resorbable categories based on the biological response to the implanted ceramics. After implantation, a thin fibrous tissue layer forms on the surface of a bio-inert ceramic to generate a minimum tissue response and poor bio-integration 
because of the separation between the surrounding tissue and the implant surface. Bioactive and resorbable ceramics tend to form chemical bonds with the host tissue that facilitate biointegration. Resorbable materials are resorbed over time and are replaced by host tissues. Some of the key challenges associated with using bioinert implants other than fibrous capsule formation include bacterial infection, chronic inflammation, and constant physical discomfort. ${ }^{24}$ However, bioactive ceramics help in biointegration with the surrounding tissue and they offer additional benefits by imparting antibacterial activity ${ }^{25}$ and augmenting angiogenesis. ${ }^{26}$ Bioactive ceramics are brittle and have poor strength and fatigue resistance. Thus, bioactive ceramics are not preferred for use alone as load-bearing implants. The application of bioactive ceramics as a coating material on implants can overcome this limitation and offer the desired combination of load-bearing properties of the substrate and the bioactivity of the coating. Aside from bioactivity, coatings can help in modulating the degradation rate of rapidly degrading materials and enhance their surface hardness.

Besides coatings, mechanical surface treatments of the nearsurface or bulk biomaterials are considered potentially costeffective and efficient strategies to enhance the bio-corrosion performance. As these processes do not deal with any additional new materials except for the original base substrate material, there are no additional challenges associated with biocompatibility. A unique advantage of the mechanical treatments over the coating process is that it improves the biomechanical integrity of the material in terms of increased strength ${ }^{27}$ and fatigue resistance ${ }^{28,29}$ of implants. Different mechanical surface treatments such as machining, shot peening, ball burnishing, and laser peening have been studied predominantly on Mg-based alloys, with fewer reported attempts on other biodegradable alloys. Biodegradable polymers are generally too soft and are not subjected to such treatments.

Recognizing the benefits of coating and surface mechanical treatments on degradable materials, there have been several attempts in recent years to modify the surface of resorbable implants. In this review article, we first focus on the overview of the polymeric and metallic materials used to develop biodegradable implants. Next, the emerging trends and current state of the art in the field of bioactive ceramic-based coatings and surface mechanical treatments on degradable biomedical implants are summarized in the review. The first part of the article highlights the various categories of bioactive ceramics and their application in the coating of biomaterials. We also describe the deposition methodologies used to prepare the coatings. The second part presents various surface mechanical treatments to modify the corrosion and biomechanical properties of degradable Mg-based biomaterials. Finally, the gaps and opportunities for the future for this field are highlighted.

\section{Clinical significance of biodegradable implant materials}

In order to address the stress shielding and secondary surgical intervention associated with permanent metallic implants, biodegradable materials have attracted significant attention and are being widely considered for orthopedic implants and cardiovascular stenting. ${ }^{22,30,31}$ Gradual degradation with a suitable rate while providing mechanical and surface integrity is crucial to realize the functional benefit of biodegradable materials. Despite recognizing their potential benefits, there are still limited choices of biodegradable materials, and researchers are continuously exploring new types of materials or improving the existing ones to achieve the desired functionality. Biodegradable metals and polymers are widely used biomaterials as implants/devices. The following section briefly summarizes the state-of-the-art development of these two types of biodegradable materials in recent times.

\subsection{Fe-based degradable alloys}

Owing to their superior mechanical properties, such as high strength (up to $1450 \mathrm{MPa}$ ) and high ductility (up to $80 \%$ elongation), Fe-based biodegradable metal alloys have been studied as potential degradable implants such as stents in earlier times. ${ }^{32}$ In vivo animal tests reported that while Fe-based alloys did not show any significant evidence of inflammatory response or systemic toxicity to the host immune cell, they exhibited two main limitations - (1) slow degradation (Fe stent remained intact and maintained its mechanical integrity in 6 to 18 months follow up post-surgery). Fe-based implants usually have a degradation rate of less than $1 \mathrm{~mm} /$ year, and the release of Fe ions takes place at ppm level in vitro, ${ }^{33,34}$ (2) ferromagnetism of Fe causing incompatibility with crucial medical devices such as MRI for diagnosis and assessment. It may limit full-body scanning at security checkpoints. These observations motivated researchers to explore new alternative approaches to increasing the degradation rate and minimizing the detrimental effect of ferromagnetism.

One alternative was to introduce different alloying elements such as manganese ( $\mathrm{Mn})$, palladium (Pd), tungsten (W), tin $(\mathrm{Sn})$, boron (B), carbon (C), silicon (Si), cobalt (Co), etc., into Fe to accelerate the corrosion rate while maintaining mechanical integrity. For instance, the Fe30Mn6Si alloy showed a higher degradation rate than the Fe30Mn alloy while minimizing magnetic susceptibility. ${ }^{35}$ Other alloying elements, namely, Co, W, B, and C, were shown to improve the yield and ultimate strength of $\mathrm{Fe}$, but $\mathrm{Sn}$ caused a reduction in overall mechanical properties. ${ }^{36}$ Adding Mn and Pd elements together into Fe in an appropriate ratio also increased the corrosion rate. For example, the degradation rate of $\mathrm{Fe}-10 \mathrm{Mn}-1 \mathrm{Pd}$ accelerated ten times that of low carbon steel. ${ }^{37}$

In addition to the alloying elements, the choice of manufacturing route also affects the microstructural and surface characteristics of Fe-based alloys. For example, a highly porous Fe-Mn alloy produced by powder metallurgy, inkjet 3D printing, and electroforming showed faster in vitro degradation than the same alloy made by the traditional casting process. $^{38-40}$ In this regard, the primary reason for the faster degradation is smaller grains with more grain boundaries and microstructure defects which are more susceptible to corrosive attack. Furthermore, the porous surface texture allows the 
corrosion medium to penetrate into the materials, thereby accelerating the degradation rate.

To achieve a faster degradation rate of pure Fe, a variety of secondary phases were added into the Fe matrix to generate micro-galvanic corrosion between the Fe matrix (anode) and secondary phases (cathode). W and carbon nanotubes (CNTs) are conductive and act as superior cathodes. Yet, the in vitro corrosion tests demonstrated a marginal enhancement of the degradation rate, other than an increase in strength, when secondary phases (W and CNTs) are added into the Fe alloy. ${ }^{41}$ Therefore, they might be a good choice for high load-bearing permanent implants instead of biodegradable ones.

Unfortunately, there are limited animal trials showing an unfavorable degradation rate of Fe-based biodegradable materials. For instance, Feng et al. deployed bio-corrodible nitrided iron stents in juvenile pig iliac arteries, and at three or six months post-operation, the stented vessels remained well patented. ${ }^{42}$ So, the results indicate that the degradation of Fe is minimal. In other words, Fe-based alloys do not completely degrade. Because of these, Fe-based alloys still face challenges for potential use in clinical applications, and perhaps more studies are needed to revolutionize the desired properties of Fe-based biodegradable materials.

\subsection{Mg-based degradable alloys}

Magnesium ( $\mathrm{Mg}$ ) is essential to human metabolism and is the fourth most abundant cation in the human body. In addition, $\mathrm{Mg}$ is a cofactor for many enzymes, which stabilizes the structure of DNA and RNA. Mg exhibits fast corrosion in the chloride-containing physiological environment. Thus, $\mathrm{Mg}$ has emerged as a biodegradable and biocompatible material for potential use as implants. Initially introduced by the Australian-German physician Erwin Payr, Mg has been used for recovering joint motion for bone fracture fixation with wires and pegs as intramedullary rods. ${ }^{43}$ Later, the use of Mg sheets was studied for restoring joint motion in animals and humans. However, the rapid generation of hydrogen/hydroxide anions due to the corrosion in $\mathrm{Mg}$ could pose serious problems for patients. For instance, such severe side effects of rapid generation of hydrogen may prevent the possible application of an $\mathrm{Mg}$ stent in the blood circulating vascular system. ${ }^{44}$ Therefore, the rapid degradation of pure $\mathrm{Mg}$ due to accelerated corrosion in a physiological environment is found to be the main concern and prevents the use of $\mathrm{Mg}$ as an implant in bone or joint repair procedures.

In order to overcome the challenge posed by pure $\mathrm{Mg}$, researchers have explored the potential opportunity of improving the corrosion performance by alloying various appropriately selected elements with $\mathrm{Mg}$. For instance, metals such as zinc $(\mathrm{Zn})$, calcium $(\mathrm{Ca})$, aluminum $(\mathrm{Al})$, silver $(\mathrm{Ag})$, yttrium $(\mathrm{Y})$, zirconium ( $\mathrm{Zr}$ ), neodymium (Nd), and $\mathrm{Mn}$ have been used as alloying elements to enhance the mechanical properties and corrosion behavior. $\mathrm{Mg}-\mathrm{Ca}, \mathrm{Mg}-\mathrm{Ca}-\mathrm{Zn}$, and $\mathrm{Mg}-\mathrm{Zn}$ are a few examples of Mg-based alloys. Cha et al. implanted and observed a bone screw made of as-extruded biodegradable $\mathrm{Mg}-5.0 \mathrm{Ca}-1.0 \mathrm{Zn}$ alloy on the femoral condyle of a New Zealand white rabbit for 24 weeks. ${ }^{45}$ Histological and micro-computed tomographic analysis shows the new bone formation and modeling with reduced bubble formation and foreign body response around the progressively degraded implant sample.

Thus, with a suitable selection of alloying elements and their compositions, the microstructure of a $\mathrm{Mg}$ material can be designed in such a way that the mechanical properties become similar to those of cancellous bone, hence making it ideal for use as a bone substitute. Recently, Farraro et al. ${ }^{46}$ conducted case studies exploring the efficacy of Mg-based alloys in tissue engineering. Both in vitro and in vivo studies reveal an improved performance of the interference screw in terms of joint stability and graft function with gradual complete degradation of $\mathrm{Mg}$ alloys.

Li et al. ${ }^{47}$ developed pins made of Mg-Ca alloys by varying the Ca concentration and using different fabrication techniques, implanted them into left and right rabbit femoral shafts, and monitored the degradation process for 1,2 , and 3 months. Initial cytotoxicity tests showed that the Mg-1.0Ca alloy did not induce any toxicity in the cells. Periodic observation of implanted pins revealed that $\mathrm{Mg}-\mathrm{Ca}$ alloy pins degraded gradually during the test period, as observed by the reduction of the pin diameter. Furthermore, new bone was found to be formed around the $\mathrm{Mg}-\mathrm{Ca}$ alloy pins, indicating the superior mechanical integrity and osteogenesis of $\mathrm{Mg}-\mathrm{Ca}$ alloy pins around the bones. A ternary alloy of magnesium with alloying elements such as $\mathrm{Zn}$ and cerium (Ce) was studied by Behera $e t$ al. ${ }^{48}$ The ternary alloy showed the best corrosion resistance potential compared to binary $\mathrm{Mg}-\mathrm{Zn}$ and $\mathrm{Mg}-\mathrm{Ce}$ alloys. Furthermore, they showed that the ternary alloy exhibited the highest osteogenic differentiation potential compared to other alloys with a good combination of mechanical and degradation properties.

$\mathrm{Mg}$ alloys containing $\mathrm{Zn}$ and $\mathrm{Mn}$ elements (e.g., $\mathrm{Mg}-2 \mathrm{Zn}-$ $0.2 \mathrm{Mn}$ and $\mathrm{Mg}-1.2 \mathrm{Mn}-1.0 \mathrm{Zn}$ ) were studied by Zhang et al. ${ }^{49}$ The alloys showed satisfactory mechanical properties and biodegradation performance. However, it was shown that $\mathrm{Mn}$ and Zn-based alloys degraded relatively faster. For instance, a 9-week implant of $\mathrm{Mg}-\mathrm{Zn}-\mathrm{Mn}$-based alloy revealed $10-17 \%$ degradation, whereas, after 8 weeks, the degradation of the same implant increased up to $54 \%$.

Therefore, it is evident that unlike Fe-based alloys, Mg-based alloys showed very promising results in terms of degradation and are highly regarded as potential biodegradable implant material candidates. Nevertheless, the faster degradation with simultaneous loss of mechanical integrity is still the primary impediment in the clinical use of Mg-based alloys. This indicates that new ways of controlling the degradation rate matching with bone healing while maintaining favorable biomechanical integrity are crucial to leverage the full benefits of the Mg-based degradable implant/device material.

\subsection{Polymer-based degradable materials}

Like metal-based degradable materials, biodegradable polymers are widely used as important bone repair implants and for tissue engineering applications, where load-bearing by an implant is not an essential requirement. ${ }^{50}$ There are two major classes of polymers - natural (e.g., chitosan, silk fibroin, 
collagen, etc.) and synthetic (e.g., PLA, PCL) polymers. However, because of high physiological activity, high degradation rate, and poor mechanical properties, natural polymers have limited application. Collagen is generally used as a decellularized tissue construct prepared by physical, chemical, or enzymatic decellularization of tissues. The immune response and sterilization are some of the key limitations associated with collagen. ${ }^{5}$ Chitosan is another naturally occurring degradable polymer. Owing to its poor strength, chitosan is primarily used as a hydrogel and sponge in biomedical applications. ${ }^{4}$ Silk fibroin is obtained by degumming of silk cocoons. It is used in drug delivery and tissue engineering applications. ${ }^{6}$ Silk fibroin-based coating was applied on magnesium alloys to improve the corrosion resistance. ${ }^{51,52}$ Instead, researchers have intensely focused on developing synthetic polymers with tailored properties to address the stringent requirements of medical devices/implants. Broadly, three synthetic degradable polymers, namely PLA, PGA, and PCL, are commonly studied, as their safe use and degradation within the body have been demonstrated. Historically, surgical sutures and meshes have been prepared from these polymers. ${ }^{53}$ PLA was first reported in 1960 and used as rods for mandibular fractures in dogs. Since then, the use of degradable PLA has ramped up with the continual development of new derivatives of PLA, such as L-PLA and DL-PLA. ${ }^{8}$ Based on glycolic acid, synthetic PGA has high crystallinity, melting point, and low solubility and was first introduced in a similar timeline of PLA as degradable suture lines. ${ }^{54}$ But PGA degrades at a relatively faster rate due to its hydrophilic surface properties. To address this limitation, a combination of a copolymer of PLA and PGA, forming a new PLGA variant, is developed and used as biodegradable fibers. A very unique and popular PLGA bone fixation product is the Lactosorb Craniomaxillofacial Fixation System developed by Biomet. On the other hand, PCL, a biodegradable aliphatic polyester, is predominantly employed for use in implants. Due to its hydrophobicity and high crystallinity, PCL shows much slower degradation than PLA and PGA. ${ }^{55}$ Furthermore, PCL can be easily formed into various geometric shapes, making PCL a popular candidate as a medical implant/device in the medical industry. ${ }^{56}$ Apart from these, synthetic degradable polymers have been successfully prepared from naturally occurring monomers such as polyols $^{57}$ and plant oils ${ }^{58,59}$ for various biomedical applications, including drug delivery and bone tissue engineering scaffolds. Several factors such as easy availability, low cost, and high reactivity of the monomers make them attractive substitutes prepared from renewable resources for degradable polymer synthesis over polymer derived from petrochemical sources.

Biodegradation of polymeric implants in the human body fluid environment occurs through two key mechanisms. First, it starts with physical biodegradation where microorganism attacks the polymer, causing hydrolysis and ionization to form polymer-like oligomer debris. Second, the polymer degrades through chemical reactions and direct interaction with the abundance of microorganisms or enzymes, resulting in micro molecules forming carbon dioxide and water by-products. ${ }^{60}$ Despite excellent degradation properties and biocompatibility, biodegradable polymers have very limited use for diverse medical devices applications. This is mainly due to its very low stiffness and strength, X-ray transparency, and in many cases, accelerated degradation and foreign body reactivity, depending on individual patients. As a result, further surface modifications of biodegradable polymers are often sought after to control the degradation rate, enhance the biocompatibility, and improve the mechanical properties.

\section{Bioactive ceramic coatings}

In this section, we describe a variety of bioactive ceramics that have been successfully applied to degradable biomaterials. They offer several benefits such as antimicrobial activity, tissue formation activity such as osteogenesis, angiogenesis, and other properties such as corrosion resistance and mechanical properties (Fig. 1).

\subsection{Zinc oxide}

Zinc oxide $(\mathrm{ZnO})$ is widely used in food packaging and textile coating applications as an antimicrobial agent. A variety of mechanisms underlying the antibacterial activity of $\mathrm{ZnO}$ particles have been reported. $\mathrm{Zn}^{2+}$ ions released from the particles damage the bacterial membrane, resulting in leakage of intracellular matter. The generation of reactive oxygen species (ROS) by $\mathrm{ZnO}$ and its penetration into the bacterial cell envelope are among the other proposed mechanisms. ${ }^{61}$ Nevertheless, the mechanism underlying the antimicrobial action of $\mathrm{ZnO}$ particles continues to be an active topic of research. There are also several mechanisms reported in the literature that describe the osteogenic activity of $\mathrm{ZnO}$. The release of $\mathrm{Zn}^{2+}$ ions from the $\mathrm{ZnO}$ particles primarily enhances osteocalcin expression by activating the mitogen-activated protein kinase pathway. Upregulation of $\mathrm{Z} 1 \mathrm{P} 1$ expression, a transporter of $\mathrm{Zn}^{2+}$ ions, promotes the RUNX2

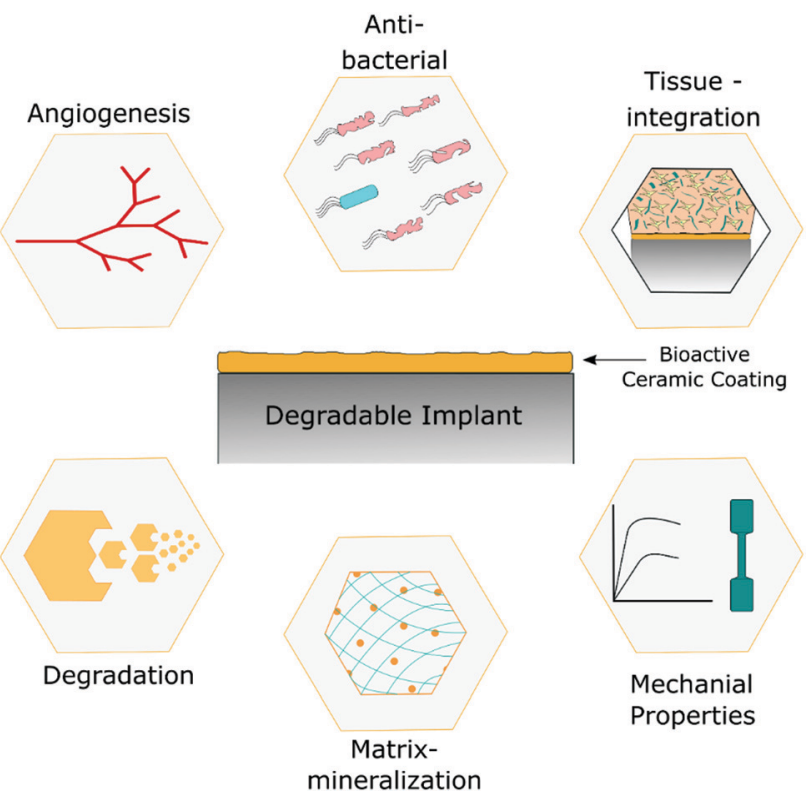

Fig. 1 Bioactive ceramic-coated implants and their potential role in improving the overall performance of the implant. 
gene expression. ${ }^{62}$ Upregulation of these genes is shown to improve new bone formation. On contact with water molecules, $\mathrm{ZnO}$ particles generate $\mathrm{Zn}-\mathrm{OH}$ functional groups at the surface. These groups act as nucleation sites for hydroxyapatite (HA) formation and further enhance the mineralization process to support osteogenesis. ${ }^{63}$ It has also been shown that $\mathrm{ZnO}$ coating helped in stimulating the macrophage polarization to both M1 and M2 phenotypes and improve the osteogenic activity. Thus, $\mathrm{ZnO}$ also enhances osteogenesis by modulation of the immune response. ${ }^{64} \mathrm{ZnO}$ particles have been widely explored in anticancer applications. The large release of $\mathrm{Zn}$ ions causes an increase in ROS levels that induced cancer cell death by apoptosis. ${ }^{65} \mathrm{ZnO}$ exhibits anti-inflammatory activity by suppressing the gene and protein expression of pro-inflammatory cytokines such as iNOS, COX-2, IL-1 $\beta$, IL-6, and TNF- $\alpha$. These antioxidant properties make $\mathrm{ZnO}$ an attractive ingredient in sunscreens and for the treatment of acne and piles. ${ }^{66}$ These numerous properties of $\mathrm{ZnO}$ make it ideal for modifying the surface of the degradable implant.
Cho et al. showed that a coating of $\mathrm{ZnO}$ on a 3D printed PCL/ HA composite enhanced the antibacterial properties of the scaffold. In addition to its antibacterial action, the release of ions from the $\mathrm{ZnO}$ coating also improved the cell attachment and promoted mesenchymal stem cell differentiation. They further showed that the release of ions from the coating depends on the coating thickness on the scaffold surface, which was deposited by magnetron sputtering. The antibacterial potential increased with the increased thickness of $\mathrm{ZnO}$ coating, as revealed by the plate count method along with SEM and live-dead imaging (Fig. 2). A coating thickness of $100 \mathrm{~nm}$ imparted the best combination of antibacterial and bioactive properties to the scaffold. ${ }^{67}$ Bacterial attachment and encrustation are the significant clinical challenges encountered after implanting urinal stents, which cause inflammation and discomfort to the patient. A coating of $\mathrm{ZnO}$ was applied on PLA films using the doctor blade technique. ZnO-coated PLA films showed improved antibacterial potential compared to the bare film.

(a)
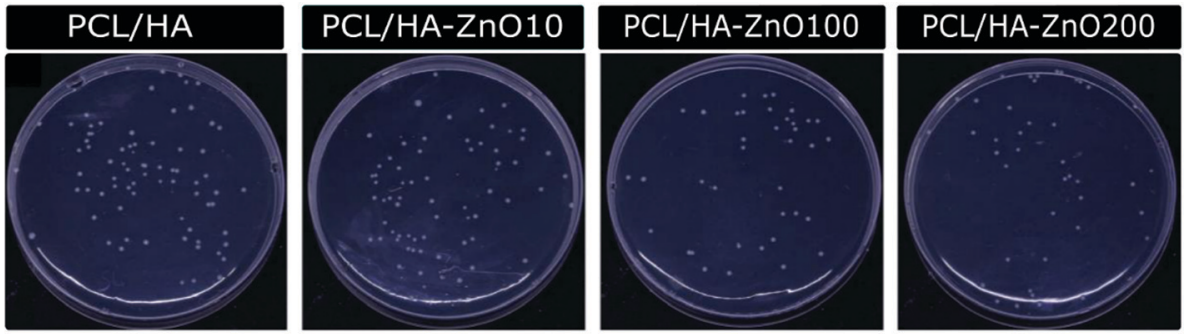

(b)
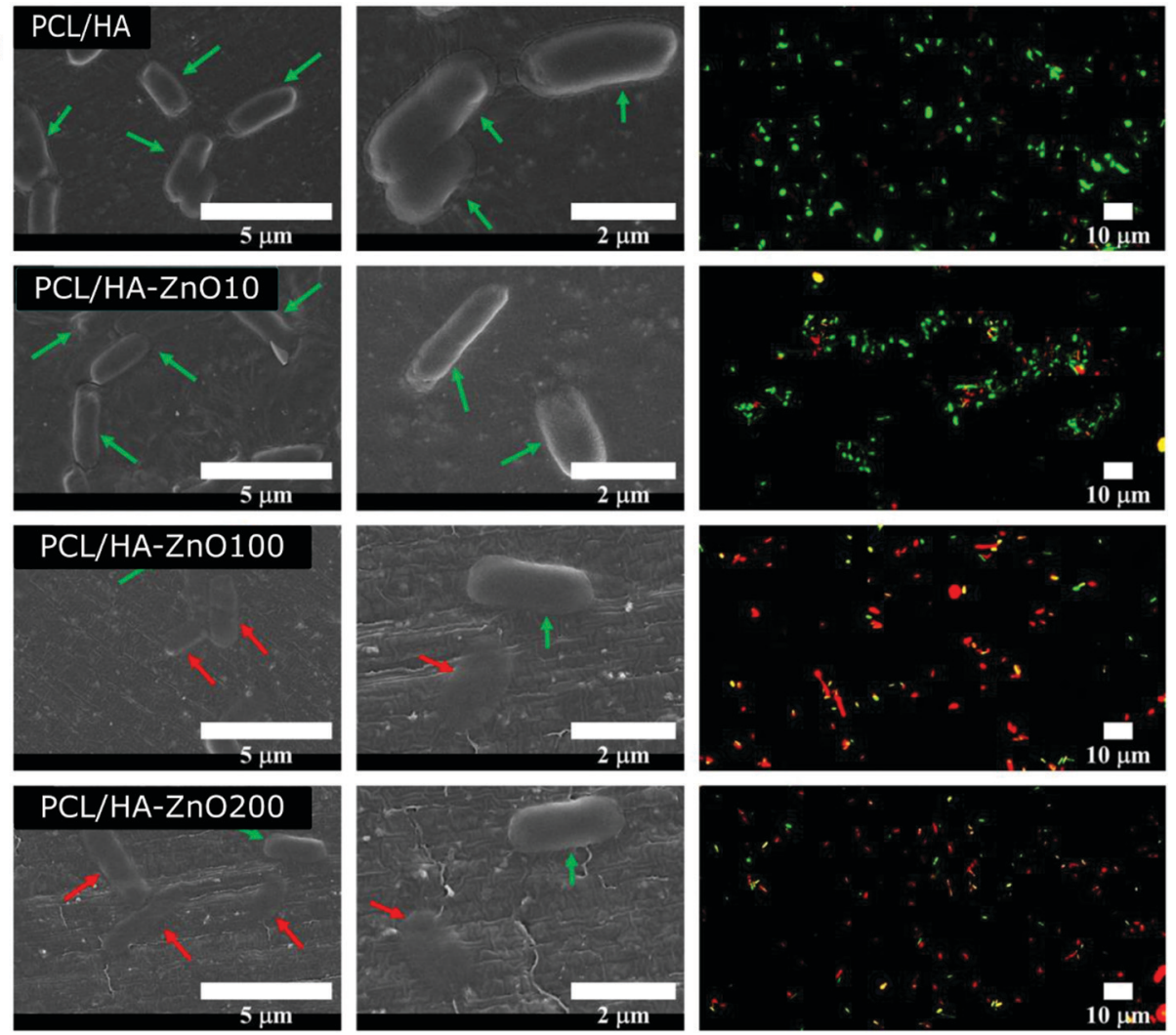

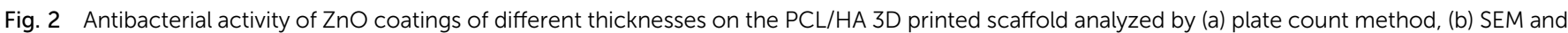
live-dead fluorescence imaging (dead bacteria in red and live bacteria in green) [Reprinted with permission from ref. 67. Copyright 2020 MDPI]. 
The coating of $\mathrm{ZnO}$ was fully degraded after three weeks of incubation in artificial urine and displayed limited deposition of encrustation on films, demonstrating the potential of such ZnO-coated polymers for developing resorbable stents. ${ }^{68}$

As stated above, the rapid corrosion rate of $\mathrm{Mg}$ limits its clinical use to prepare implants. The surface modification with a suitable bioactive ceramic coating is one of the promising solutions to control the corrosion of $\mathrm{Mg}$-based implants. $\mathrm{ZnO}$ coating has been applied on $\mathrm{Mg}$ implants to improve their corrosion resistance along with antibacterial potential. Undoped $\mathrm{ZnO}$ coating was deposited on magnesium implants by magnetron sputtering to improve their corrosion resistance and surface hardness. ${ }^{69}$ Composite $\mathrm{ZnO}$ coatings on $\mathrm{Mg}$ alloys such as Ag-doped $\mathrm{ZnO},{ }^{70}$ PLA-ZnO, ${ }^{71}$ PCL-chitosan (CS)-ZnO, ${ }^{72}$ and polypyrrole (Ppy)- $\mathrm{ZnO}^{73}$ were reported to improve the corrosion resistance and antibacterial potential compared to the bare surface.

\subsection{Zirconium oxide}

Zirconium oxide (zirconia) has widespread applications as dental implants and in the coating on metallic implants to increase their corrosion resistance. Hip implants ${ }^{74}$ and dental implants ${ }^{75}$ prepared from zirconia have shown long-term clinical success because of their good biocompatibility, strength, and wear resistance. Zirconia has been reported to activate the BMP4 gene. ${ }^{76}$ This gene is involved in early bone development and induces bone growth. Furthermore, it was reported that zirconia influences the spreading and proliferation of osteoblasts and stem cells with improved cell division and helps in forming a well-organized monolayer of cells. These cell-implant interactions prevent the aseptic loosening of the implant and facilitate its bio-integration. ${ }^{77}$ Thomas et al. demonstrated that zirconiapolydimethylsiloxane hybrid films improve the growth and viability of osteoblasts and fibroblasts. Thus, coatings prepared using this hybrid material enhance the bio-integration at the
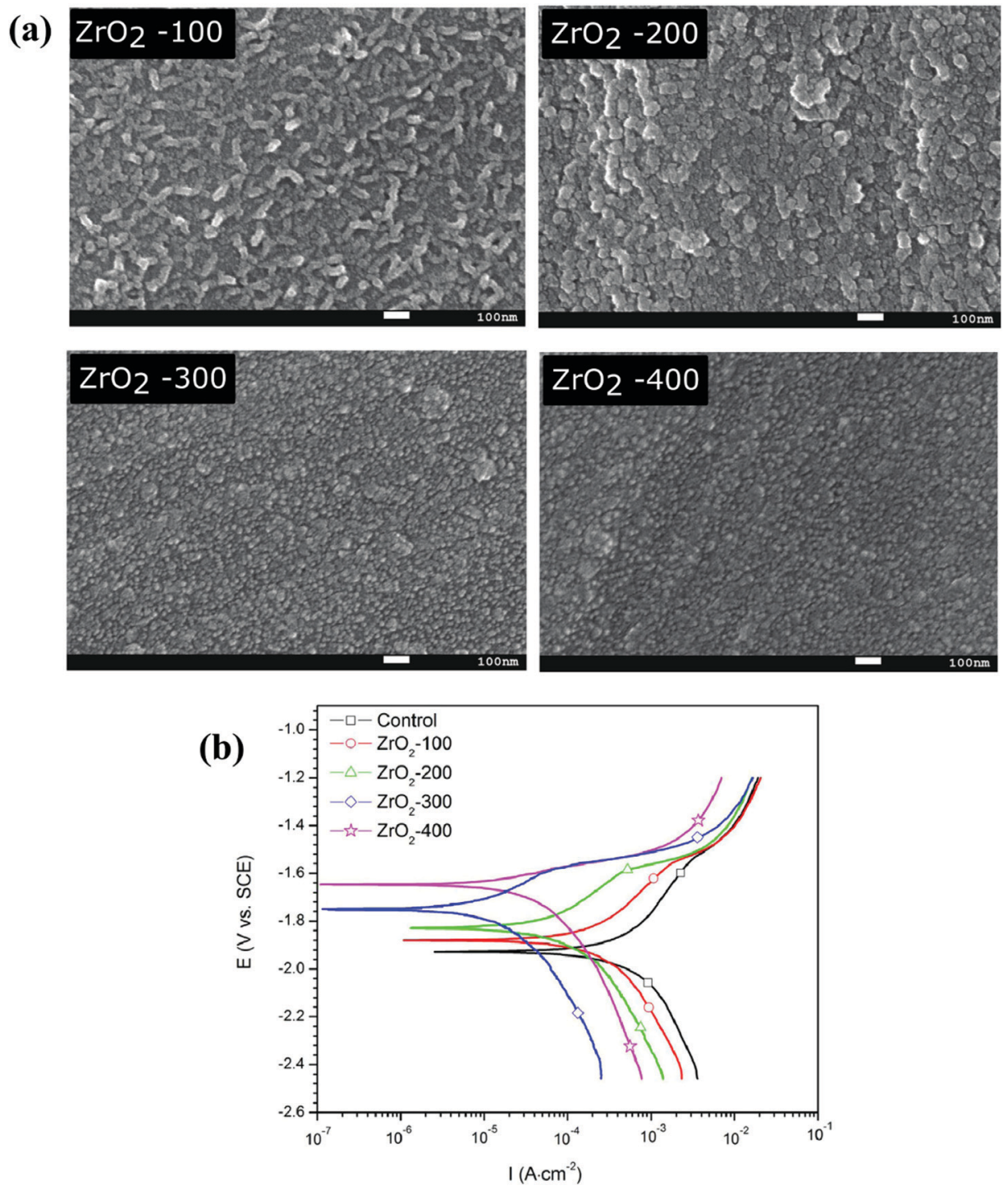

Fig. 3 (a) Surface morphologies of zirconia $\left(\mathrm{ZrO}_{2}\right)$ with different cycles of atomic layer deposition (i.e., 100, 200, and 300) imaged by SEM, (b) potentiodynamic polarization curves of different coated samples along with the uncoated sample [Reprinted with permission from ref. 82 . Copyright 2017 Elsevier]. 
tissue-implant interface. ${ }^{76}$ Seweryn $e t$ al. reported the atomic layer deposition technique to generate uniform thickness zirconia coating on the substrate. They showed that the coating had biomimetic properties when tested with osteoblasts and thus increased the osteogenic potential with enhanced bone integration. ${ }^{78}$ Zirconia is also used as an antimicrobial agent in biomedical applications. The following antibacterial mechanism has been proposed in the case of zirconia. Zirconia interacts with the thiol groups found in the respiratory enzymes in bacterial cells. It binds to the bacterial cell membrane and disturbs the

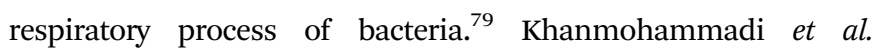
described the antimicrobial activity of zirconia against $E$. coli and $S$. aureus. Zirconia-doped PCL/cellulose nanofibers were prepared by electrospinning. These coated scaffolds also showed antifungal activity when tested against Candida albicans. ${ }^{80}$ These studies show the use of zirconia as a material to improve osseointegration along with effective osteogenic and antibacterial properties.

Huang et al. showed that the coating of zirconia on the AZ91 $\mathrm{Mg}$ alloy improved the corrosion resistance along with surface hardness. ${ }^{81}$ Furthermore, Yang et al. showed that a zirconia coating on the $\mathrm{Mg}$-Sr alloy improved the corrosion resistance along with enhanced attachment, proliferation, and differentiation of osteoblasts. They used atomic layer deposition to coat the alloy surfaces with zirconia with a different number of cycles. The coating thickness increased with the number of cycles, which improved the corrosion resistance, as shown in Fig. $3 .^{82}$ Therefore, zirconia coating can be used to tailor the biocompatibility and corrosion resistance of degradable orthopedic and dental implants.

\subsection{Titanium oxide}

Titanium oxide is widely used in biomedical applications as an antibacterial and anticorrosive agent. Titanium oxide exhibits photocatalytic activity that generates electron-hole pairs on exposure to UV light. These electron-hole pairs produce ROS in the vicinity of the particle. ROS oxidizes bacterial intracellular enzymes, reduces respiratory action, and subsequently causes bacterial death..$^{83}$ Improvement in the antibacterial properties of polylactic acid/titanium oxide films after the doping of titanium oxide nanoparticles was reported by Feng et al..$^{84}$ They showed that the composite film inhibits the growth of bacteria when compared with the pristine film. According to Matsuno et al. ${ }^{85}$ PLA surface modified with titanium oxide improves the initial attachment of fibroblasts and their subsequent proliferation. Titanium and its alloys have been frequently used in the orthopedic field due to their high strength and low density. Titanium and alloys are completely inert as they spontaneously form a layer of titanium dioxide on the surface. This oxide layer protects the implant from body fluids and tissue corrosion. As the oxide layer comes in contact with water, it forms Ti-OH groups on the surface. Similar to the $\mathrm{ZnO}$ layer, these groups act as nucleation sites for different calcium phosphate compounds owing to the close match between the crystallographic planes of the oxide and calcium phosphate. ${ }^{86}$ The similarity of calcium phosphate with the bone mineral phase augments the integration of the implant with contacting tissue. Thus, the titanium oxide layer imparts anticorrosive properties and tissue bonding ability to $\mathrm{Mg}$ implants, which has been leveraged in a few studies. ${ }^{87-89}$

The in vivo osseointegration potential of the polyetheretherketone implant coated with titanium oxide was reported by Tsou et $a l .{ }^{90}$ They showed that a titanium oxide coating prepared by arc ion plating not only improves the compatibility when tested with osteoblasts but also enhances the new bone formation and tissue integration. This study demonstrates that titanium oxide coating can be deposited on degradable polymer implants to enhance osseointegration and antibacterial properties, although such coatings have not been applied on degradable polymeric implants.

\subsection{Vanadium oxide}

Vanadium is one of the transition metal elements. Like most of the transition metals, vanadium also has multiple oxidation states. Among many oxides of vanadium, vanadium pentoxide (vanadia) nanostructures have been used in biomedical applications as an antibacterial agent. There are two mechanisms reported for the antibacterial properties of vanadia nanostructures. The first mechanism was reported by Anicic et al. in $2017 .{ }^{91}$ They showed that vanadia nanostructures mimic the myeloperoxidase-like catalytic activity of human neutrophils. The role of this enzyme is to kill the bacteria by the transformation of hydrogen peroxide to hypochlorite. In addition to this activity, it also promotes the growth of mammalian cells via the insulin-mimicking effect. This bioactivity was observed at a low concentration of vanadate ions in the system. At low concentrations, these ions also help in tissue repair and improve the bone formation rate in vivo. In contrast, a high concentration of vanadate ions is toxic to human cells. ${ }^{91}$ Hence, control and sustained release of vanadate ions are key to leverage the above said beneficial properties. Vanadia nanowires/poly(lactic-coglycolic acid) composites have been shown to satisfy the above criteria and enhance the antibacterial activity. Vanadia nanoplates have been shown to increase the generation of ROS in bacterial biofilms. Increased ROS production causes bacterial death. Raman spectral mapping demonstrated the changes in biomolecular signals from bacteria following interactions with vanadia nanoplates. ${ }^{92}$ Menazea et al. showed that the addition of vanadia to chitosan/polyvinyl alcohol coating enhances the antibacterial properties of the film. The antibacterial activity of the films increased with an increase in the doping of vanadia nanoparticles up to a saturating amount. ${ }^{93}$ In addition to this, vanadia coating deposited on $\mathrm{Mg}$ alloys was prepared by dip-coating ${ }^{94}$ and microarc oxidation ${ }^{95}$ to improve the corrosion and wear resistance. All these observations from several studies demonstrate the potential of vanadia as a surface coating material for implants to improve the corrosion resistance and antibacterial properties toward minimizing implant-associated infections and facilitate healing by controlling the release of hydrogen gas in the process of corrosion.

\subsection{Copper oxide}

Copper oxide nanoparticles have been successfully applied in a wide variety of fields, including nanoelectronics, solar cells, 
and catalysis. Apart from these applications, it also possesses remarkable antibacterial properties. The antibacterial properties of copper oxide are attributed to the release of $\mathrm{Cu}^{2+}$ ions, which causes severe damage to the negatively charged lipids and proteins of the bacterial cell wall. Moreover, copper ions have high redox properties, which generate ROS. ROS causes DNA damage and modification of cellular components in bacterial cells. ${ }^{96}$ According to Escobar et al., doping of copper oxide nanoparticles into the PCL electrospun fibers resulted in significant bactericidal action on Gram-negative bacteria compared to Gram-positive bacteria. This difference is because Gram-negative bacteria have thin cell walls in contrast to Gram-positive bacteria, resulting in easier exposure to copper ions. ${ }^{97}$

Munoz et al. prepared copper oxide infused PCL nanofibers by electrospinning. Their work reveals that the infused fibrous mats showed an antifungal effect against various species of candida. Furthermore, they also observed that the cell morphology of candida was disrupted in a dose-dependent manner on the infused mat. ${ }^{98}$ The toxicity of copper ions released from nanoparticles on mammalian cells along with bacterial cells was first reported by Balcucho et al. ${ }^{99}$ They prepared a composite film of PCL and copper nanoparticles by the solution blending method. They observed that the composite film showed minimal DNA damage and significant cell viability of human foreskin fibroblasts while showing excellent antibacterial potential against $S$. aureus. Badaraev et al. coated the surface of the electrospun PLA scaffold with copper/copper oxide by magnetron sputtering. They observed that the coating remarkably improved the antibacterial potential of the scaffold. ${ }^{100}$ Such a strategy of depositing copper/copper oxide coatings on the degradable implants has significant potential for enhancing their antibacterial properties.

Copper ions have been shown to enhance the proliferation of endothelial cells and promote angiogenesis. Copper is required to activate hypoxia-induced factor-1, which is the primary transcription factor controlling the expression of vascular endothelial growth factor (VEGF). VEGF is mainly involved in the creation and maturation of blood vessels. ${ }^{101}$ This potential imparts one more biochemical aspect to the coating of copper oxide, which has been utilized in several studies to enhance angiogenesis. ${ }^{102-105}$

\subsection{Iron oxide}

Like most transition metal oxides, iron oxide also shows antibacterial potential. Various studies have reported this activity of iron oxide against Gram-positive and Gram-negative bacterial strains. The ions released from the nanoparticles attracted negatively charged bacterial cells and attached to the cell membrane or penetrated inside the bacterial cells. The primary mechanism was the production of ROS due to these ions, which disrupt the bacterial cell wall and induce DNA damage. ${ }^{106-108}$ Several strategies have been reported on the use of iron oxide to prepare coatings on polymer surfaces to improve their antibacterial activity. ${ }^{109,110}$

Apart from their antimicrobial activity, superparamagnetic iron oxide particles generate heat after applying an alternating magnetic field. Initially, this property was investigated for treating cancerous tumors, but such magnetic hyperthermia is being explored for treating implant-associated infections in more recent times. Rovers et al. ${ }^{111}$ developed a system of iron oxide particles and thermoresponsive polymer poly(butyl methacrylate-stat-methyl methacrylate) for the delivery of antibacterial drugs based on magnetic hypothermia induced by the iron oxide particles. On the application of a magnetic field to the system, the heat generated causes an increase in the temperature of the thermoresponsive polymer to its glass transition temperature. This heating causes the release of the drug-loaded in thermoresponsive polymers due to the increased diffusion rate near $T_{\mathrm{g}}$. They observed that the drug release increased up to 5 -fold after the application of the magnetic field, and the release is dependent upon the iron oxide content. A similar strategy can be implemented for the smart release of antibiotics using biodegradable and thermoresponsive polymers such as poly(lactide-co-trimethylene carbonate) to tackle implant-based bacterial infections. Numerous studies have reported using iron oxide particle's magnetic hypothermia to eradicate bacterial infection. ${ }^{112,113}$ These various properties of iron oxide can be utilized to develop drug/biomolecule eluting coatings on degradable implant surfaces to enhance the bioactivity of the materials.

\subsection{Cerium oxide}

Cerium is a rare earth metal placed second in the lanthanide series of the periodic table. Most of the rare earth metals exist in their trivalent state. However, cerium occurs in both trivalent $(+3)$ as well as tetravalent $(+4)$ states. ${ }^{114,115}$ Consequently, cerium oxide (ceria) has the unique ability to switch between the two oxidation states $\left(\mathrm{Ce}_{2} \mathrm{O}_{3}\right.$ and $\left.\mathrm{CeO}_{2}\right)$. During oxygen exchange, loss of lattice oxygen atoms in the cubic fluorite lattice causes the generation of oxygen vacancies in ceria. This vacancy can be filled by atomic oxygen, which generates a new vacancy, causing lattice oxygen mobility and rapid refilling of the surface oxygen vacancy sites. ${ }^{116}$ Ceria is widely used in various applications, such as catalytic converters, solid oxide fuel cells, ${ }^{117}$ electronics, and electrochemistry. ${ }^{118}$

In recent years, ceria has been attracting considerable attention in biomedical applications due to its redox properties. Ceria mimics superoxide dismutase (SOD) and catalase (CAT) enzymes, which act as cellular antioxidants. Korsvik et al. demonstrated that the oxygen vacancy created on the surface is mainly responsible for the SOD-mimicking activity of ceria. ${ }^{119}$ Ceria is used as an antibacterial agent in various cases. Faris et al. described the antimicrobial activity of ceria nanoparticles against both Gram-positive and Gram-negative bacteria. The interchange of the oxidation state disrupts the bacterial cell membrane and results in bacterial death. ${ }^{120}$ Antifungal activity of ceria has also been observed. ${ }^{121}$ Several studies described the ability of ceria nanoparticles to induce angiogenesis, which makes it an attractive candidate for a bioactive implant. Das et al. described that ceria nanoparticles induce angiogenesis in human umbilical vein endothelial cells (HUVECs) by regulating intracellular oxygen. ${ }^{122}$ Corroborating the angiogenic activity of 
these particles, Augustine et al. showed that infusion of nanoceria in electrospun PCL nanofibers promoted angiogenesis compared to the neat fibers. ${ }^{123}$

The ceria-loaded gelatin-alginate nanocomposite was developed by a freeze-dried method having an interconnected porous morphology. The addition of ceria to the composite helped in the reduction of ROS and promoted bone formation. Apart from biological cues, the addition of ceria enhances the composite's mechanical, swelling, and degradation properties. ${ }^{124}$ Our group also demonstrated the development of ceria particle coated PCLgelatin electrospun nanofibrous mats. Depletion of ROS is reported to be in relation to the suppression of hypotrophy in cardiac tissue. The $\mathrm{H}_{2} \mathrm{O}_{2}$ stress-induced oxidative stress level showed a remarkable reduction in cardiomyocytes cultured on decorated scaffolds. Thus it showed that coating ceria particles imparts antioxidant and anti-hypertrophic properties to the cardiac patch. ${ }^{125}$ The deposition of ceria conversion coatings on $\mathrm{Mg}$ alloys with different additives and pre-treatments has been reported in numerous studies to improve the corrosion resistance. ${ }^{126,127}$ The ceriacoated titanium substrate fabricated by spin coating showed improved antibacterial and anti-inflammatory potential. ${ }^{128} \mathrm{~A}$ similar strategy can be applied to degradable implants to impart various properties, but such studies are not reported.

\subsection{Europium hydroxide/oxide}

Europium is also one of the rare earth metals and is the most reactive lanthanide series element. Europium hydroxide/oxide ceramic materials have been studied in the last decade as pro-angiogenic materials in biomedical applications such as tissue engineering, wound healing, and treating ischemic conditions. ${ }^{129,130}$ Europium hydroxide nanorods cause an increase in the production of $\mathrm{H}_{2} \mathrm{O}_{2}$ ROS. This surge of ROS activates the enzyme called nitric oxide synthase 3, which induces the secretion of nitric oxide in the system. These molecular events stimulate new capillaries to sprout from the existing blood vessel in a process called angiogenesis. ${ }^{131}$ Patra et al. were the first to report the biological effects of europium hydroxide nanorods on the HUVECs. They showed that these ceramic nanorods promote the proliferation of HUVECs and vascular sprouting in chick embryo chorioallantoic membrane (CAM) assay, which are functional evidence of their angiogenic activity. ${ }^{132}$ These observations laid the foundation for several subsequent investigations on the pro-angiogenic activity of this material for various biomedical applications. Infusion of europium hydroxide nanorods in PCL nanofibrous mats augmented angiogenesis in vitro and in vivo. HUVECs seeded on the composite fibers showed better proliferation in comparison to neat fibers. Western blot analysis revealed increased expression of angiogenic markers in cells cultured on the nanorod-loaded electrospun mats. ${ }^{133}$ Angiogenesis and vascularization are essential phenomena in the process of wound healing and skin regeneration. Luo et al. showed the benefit of doping europium oxide nanorods in hydrogels for wound healing and skin tissue regeneration by aiding angiogenesis and suppressing inflammation at the wounded site. ${ }^{130}$ Furthermore, europium-doped bioglass also showed the ability to stimulate osteogenesis in vitro and in vivo. ${ }^{129}$ These several studies exhibit the potential of europium oxide/hydroxide ceramic materials as coating materials for polymeric or metallic implants. However, studies on their use as surface coatings on degradable materials have not been reported.

\subsection{Bioactive glass}

Specific chemical compositions of silica-based glass-ceramics containing $\mathrm{Ca}$ and phosphate ions are known for their unique binding ability to living tissues, thereby forming a strong tissue-biomaterial interface. This class of ceramics is known as bioactive glass. The first bioactive glass was reported way back in 1969, which is a quaternary system of $\mathrm{SiO}_{2}-\mathrm{Na}_{2} \mathrm{O}-\mathrm{CaO}-$ $\mathrm{P}_{2} \mathrm{O}_{5}$ and is known as 45S5 Bioglass ${ }^{\circledR} \cdot{ }^{134}$ Subsequently, several phosphate-, silicate-, and borate-based bioactive glass systems have been explored for biomedical applications. ${ }^{19}$ Bioactive glasses develop a strong bonding with hard tissues such as bone and dental tissues and also with several soft tissues. ${ }^{135}$ After forming a stable interface, a bioactive glass elicits a variety of biological responses, including new tissue formation, angiogenesis, ${ }^{102}$ bactericidal action, ${ }^{136,137}$ etc. The above said properties are associated with the time-dependent dynamic modification of the surface after implantation in a series of reactions. The bioactive glass has a natural tendency for biodegradation and releases various ions into its vicinity, which primarily depends upon the glass composition and the local $\mathrm{pH}$. When the bioactive glass surface comes into contact with body fluid, it forms a network with $\mathrm{Si}$ in the glass. This network further draws the movement of $\mathrm{Ca}$, and phosphate ions from the core to the $\mathrm{Si}$ reach layer at the surface, causing the formation of a biologically active carbonate-HA layer, which provides a bonding interface with tissue. ${ }^{138}$

The dissolution products of the bioactive glass, such as $\mathrm{Ca}$ and silicate ions, help the cells to form new tissue. The ions released from doped bioactive glass elicit additional biological responses. For example, $\mathrm{Sr}^{2+}$ stimulates bone growth, ${ }^{139,140}$ and $\mathrm{Cu}^{2+}$ helps in angiogenesis, ${ }^{102}$ whereas the release of $\mathrm{Ag}^{+}$ enhances the antibacterial potential ${ }^{136,141}$ of doped glass. These attributes of bioactive glass make it a suitable material for coating implants. The coating of glass on metallic implants imparts bioactivity, augments bio-integration, and enhances corrosion resistance. The coating of bioactive glass on the metallic implant surface has been described in numerous review papers. For example, Yadav et al. highlighted the coating of bioactive glass on $\mathrm{Mg}$ and its alloys to improve their corrosion resistance. They also summarized the effect of interfacial aspects such as the composition of bioactive glass, coating thickness, adhesive strength, and wettability on corrosion of $\mathrm{Mg}$ and its alloys. ${ }^{142}$ Sergi et al. reviewed the different methods of coating bioactive glass on metallic implants. ${ }^{135}$

On polymeric implants, bioactive glass coating provides mechanical reinforcement and tunable degradation of the polymeric substrate in addition to improved biocompatibility and bioactivity. Roether et al. reported bioactive glass coating on microporous PLA foam for tissue engineering applications. They utilized the slurry dipping method to get a uniform 
coating on the porous polymer scaffold. The in vitro biomineralization study in simulated body fluid (SBF) generated an HA layer on the surface. They further showed that the thickness of the HA layer increased with the time of incubation in SBF. ${ }^{143}$ Zhu et al. developed a mesoporous bioactive glass coating on the microporous PLA scaffold for the sustained release of an antimicrobial drug. They showed that mesoporous bioactive glass coating resulted in sustained release of an antimicrobial drug loaded in the coating to eradicate the bacterial infection, apart from improved bioactivity due to the development of the HA layer. ${ }^{144}$

Bioactive coatings were initially employed primarily for hard tissue engineering, but such coatings have been increasingly explored for soft tissue engineering over the last decade. Blaker et al. developed Ag-doped degradable polymer sutures using the dip-coating process. Their study revealed that the coated suture showed improved in vitro bioactivity and antibacterial potential compared to uncoated sutures. ${ }^{141} \mathrm{Zn}$-doped bioactive glass coating on sutures for antibacterial application is also reported in the literature. ${ }^{137}$ Thus, all these studies reveal that the bioactive glass coating provides a combination of enhanced biological and mechanical properties with tunable degradation to degradable polymeric implants.

\subsection{Calcium phosphate-based ceramics}

The family of calcium phosphate (CaP)-based ceramics are the most common bioceramics used in biomedical applications. $\mathrm{HA}$ is the most stable of $\mathrm{CaP}$ compounds at physiological $\mathrm{pH}$, because of which HA is the most exploited CaP phase among them. Other CaP-based compounds that have shown promise in biomedical applications include tricalcium phosphate (TCP), ${ }^{145}$ dicalcium phosphate dihydrate (DCPD), ${ }^{146}$ amorphous calcium phosphate, ${ }^{147}$ and octacalcium phosphate. ${ }^{137} \mathrm{HA}$ is the bioceramic of choice due to its similarity to the mineral phase of natural bone. HA has been shown to form a chemical bond with the bone and establish a robust interface between the implant and tissue, thereby providing early fixation to fasten implants with the surrounding tissue. Apart from this, fluoridated HA evokes antibacterial potential against several bacterial strains. ${ }^{148}$ In addition to fluorine, the incorporation of $\mathrm{Ag}^{149,150}$ and $\mathrm{Zn}^{151,152}$ into HA also imparts antibacterial potential. A porous HA layer can also act as a reservoir for antibacterial drugs and biomolecules, ensuring the sustained release of the stored molecules. ${ }^{153,154}$ The doping of copper in HA is known to enhance angiogenesis. ${ }^{103,104}$ Implants made out of CaP alone tend to be brittle, limiting their use in many applications. Consequently, HA emerged as an attractive coating material for biomedical implants.

The dissolution rate is important as it determines the release of $\mathrm{Ca}$ and phosphate ions from the $\mathrm{CaP}$ layer, which modulates the cellular response. For a slow degrading CaP layer, the surface topography drives the cell behavior, whereas the release of ions plays a more dominant role in fast degrading ceramic coatings. As HA has a much slower dissolution rate at physiological $\mathrm{pH}$ compared to $\beta$-TCP, biphasic calcium phosphate, a mixture of HA and $\beta$-TCP, is used to tailor the degradation rate. It has been shown that increasing the concentration of $\beta$-TCP in the mixture improved the differentiation of stem cells by upregulating osteogenic genes. This effect is associated with the increased release of the ions from the $\beta$-TCP component. ${ }^{145,155}$

HA coating on $\mathrm{Mg}$ implants can change the surface morphology and enhance corrosion resistance along with improved osseointegration. The use of CaP-based coating on $\mathrm{Mg}$ implants has been comprehensively reviewed in various articles. ${ }^{156-158}$ Although HA is a promising material for coating implants, it suffers from some limitations, such as poor adhesion strength to the substrate and insufficient chemical stability, which might compromise the implant's long-term benefit. The shot peening with ceramic balls followed by electrodeposition of DCPD coating on magnesium AZ31 alloys was shown to improve the adhesion strength of the coating along with improved corrosion resistance. ${ }^{159}$ Shi et al. prepared a composite coating of the oxide layer by micro-arc oxidation followed by the DCPD layer through electrodeposition on a magnesium AZ80 alloy substrate. They showed that the composite coating imparted excellent corrosion resistance along with enhanced deposition of appetite. ${ }^{146}$ Like bioactive glass coatings, CaP coatings improve the bioactivity along with mechanical stability and degradation of polymeric substrates. The CaP-based coating has been applied on several types of polymeric scaffolds, such as porous scaffolds prepared by porogen leaching, ${ }^{160,161}$ electrospun nanofibrous mats, ${ }^{162,163}$ and 3D printed scaffolds. ${ }^{164,165}$ Treatment of a porous composite PLA/HA scaffold with air plasma improved the nucleation of apatite when the scaffolds were incubated in SBF. Rapid healing and faster integration with bone were observed for plasma-treated composite scaffolds in vivo than pure PLA scaffolds. ${ }^{161}$ Guo et al. fabricated porous PLA scaffolds maintaining the HA layer on the pore wall using ice-HA hybrid particles as porogens. They showed that the method could be tailored to control the pore size and deposit uniformly thick HA on pore walls. ${ }^{160}$

Different surface treatments were incorporated to reduce the time duration of the biomineralization process in SBF and deposit an apatite layer. These treatments include silicate, ${ }^{166}$ ammonia alkali, ${ }^{167}$ and grafting of citric acid-polyethylene imine. ${ }^{168}$ For example, our group reported that the surface treatment with citric acid-polyethylene imine reduced the time required to form the apatite layer to 7 days from 21 to 28 days required in traditional techniques. Citric acid helps to increase the precipitation of $\mathrm{Ca}$ and phosphate ions when incubated in SBF. ${ }^{168}$ Poh et al. developed CaP-coated and two different bioactive glass-doped 3D printed PCL scaffolds. Their study revealed that the coating and incorporation of both the ceramics showed improved osteogenic potential in vitro. They implanted neat PCL scaffolds and sheep bone marrow stromal cell-seeded PCL scaffolds in Rowett Nude rats subcutaneously. The study revealed that under all the conditions, combinations of the fibrous connective tissue and adipose tissue formed inside the pores of the scaffold, confirming tissue infiltration in the scaffold. In spite of that, mature bone was not observed in vivo in any group (Fig. 4). ${ }^{169}$ Plasma spraying of HA particles on the carbon fiber/polyamide implant increased the osteogenic 


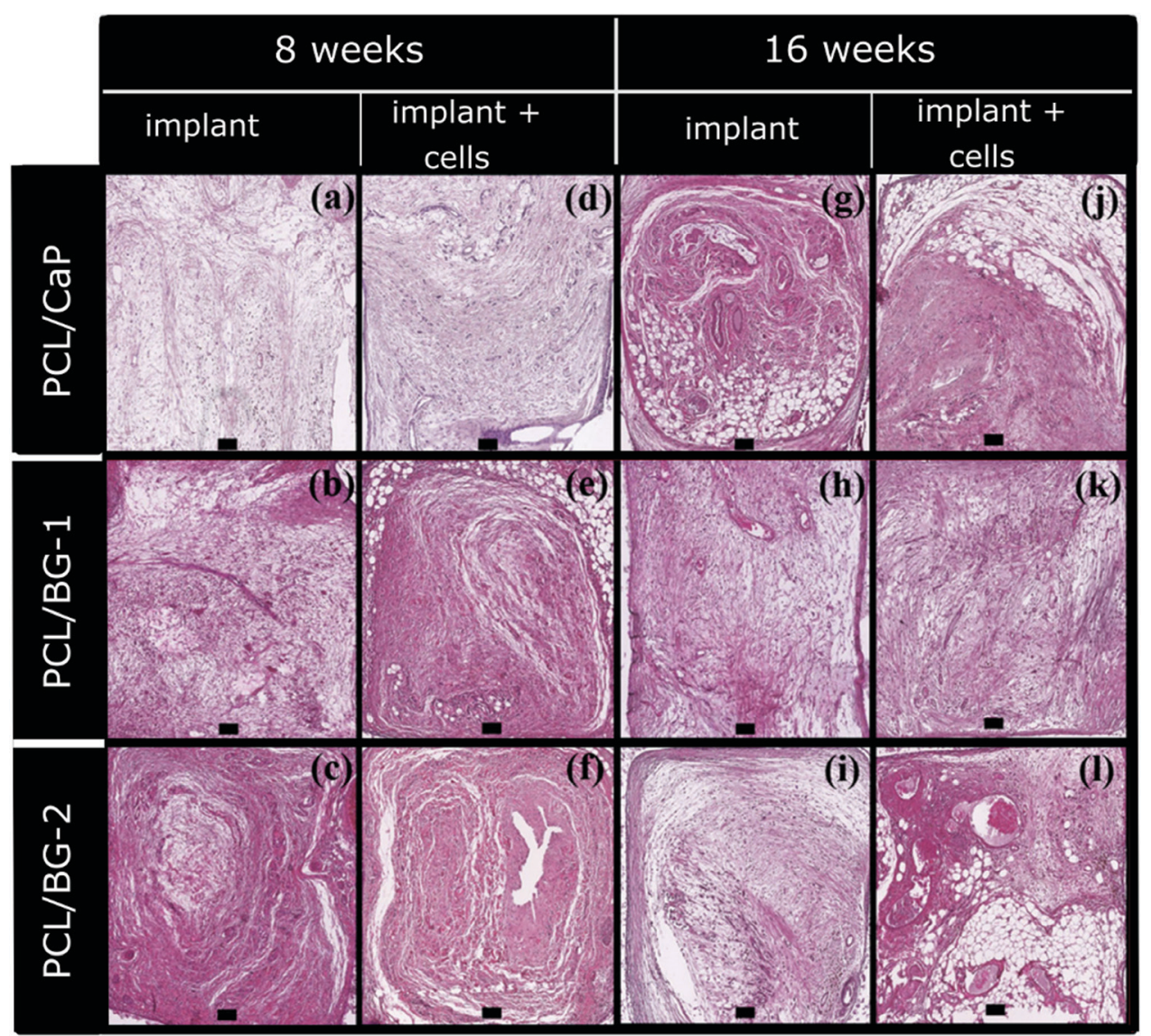

Fig. 4 Hematoxylin and eosin-stained images of CaP coated 3D printed PCL and two different bioactive glass-incorporated 3D printed PCL scaffolds implanted with and without cell seeding after 8 and 16 weeks of implantation. [Reprinted with permission from ref. 169. Copyright 2016 Elsevier].

potential of the substrate. ${ }^{170}$ A similar kind of coating method can be used for degradable polymer implants for orthopedic applications.

\subsection{Carbide and nitride-based ceramics}

Carbides and nitrides are a major class of ceramics popularly used as coatings on biomedical implants after oxides. Generally, nitrides and carbides are extremely hard ceramic materials with very high moduli. These ceramics are difficult to fabricate into different implant shapes. Hence coatings of nitrides and carbides are used on biomedical implants to improve the surface properties of substrates. Coatings of carbides and nitrides are primarily applied on metallic implants. Among the carbides, titanium carbide and silicon carbide are the most widely reported in the scientific literature. Titanium carbide is known to have superior adhesion to different metallic substrates, ${ }^{171}$ good wear resistance under dry and wet conditions, ${ }^{172}$ good corrosion resistance, ${ }^{173}$ and improved biocompatibility that mediates bio-integration when applied as a coating on a metallic substrate. The oxide layer formed on metallic implants such as titanium is brittle in nature and can fracture easily. Consequently, the underlying titanium surface can be exposed to severe corrosion in the biological environment that releases titanium particle ions inducing toxicity to adjacent tissues, resulting in inflammation and implant failure. Application of titanium carbide on the implant surface overcomes this problem by increasing the corrosion and wear resistance while maintaining biocompatibility. ${ }^{174}$ Brama et al. developed a titanium carbide coating on titanium by pulsed laser deposition. They showed that the coating improved the corrosion resistance along with enhanced growth, attachment, and osteogenic differentiation of osteoblasts in vitro. In vivo experiments in rabbit and sheep models demonstrated significant bone formation on titanium carbide-coated samples compared to neat titanium samples. ${ }^{172}$ Pushpanathan et al. showed that electrodeposited titanium carbide on the AZ8A $\mathrm{Mg}$ alloy demonstrated improved corrosion and wear potential. ${ }^{175}$

Silicon carbide has also been used to coat metallic implants to improve their corrosion resistance under biological conditions. Silicon carbide has been known for its high strength, resistance to the corrosive biological environment, and ease of deposition. ${ }^{176}$ $\mathrm{Li}$ et al. showed that silicon carbide-coated WE43 Mg alloys demonstrated anti-thrombogenic potential and improved hemocompatibility along with better corrosion resistance; thus, it can be used to coat coronary stents. ${ }^{177}$

Nitride-based ceramics are also used to coat metallic implants, given their corrosion and wear resistance, which augment their long-term success in vivo. Titanium nitride has been widely used to coat $\mathrm{Mg}$ implants. ${ }^{178-180}$ Moreover, titanium nitride coating also improves the biocompatibility of implants in a manner similar to that of carbides. Annunziata 
et al. showed that coating of titanium nitride supported the attachment and growth of mesenchymal stem cells, whereas decreased bacterial attachment and growth were observed. ${ }^{181}$ The application of titanium nitride for coating medical implants has been summarized in other review articles. ${ }^{182,183}$

\subsection{Miscellaneous ceramics}

Some of the bioceramics have received significant attention and were used as coatings on various biomaterials, including degradable biomaterials, as described above. However, several other ceramic coatings have also been attempted, although they have received less attention. Moreover, these coatings have been attempted on non-degradable substrates, although they can also be tried for degradable biomaterials. This section briefly compiles the work done on these less explored ceramic coatings.

Strontium is present in a minimal amount in human bones. Strontium ions have a charge to size ratio that is similar to that of and can thus replace $\mathrm{Ca}^{2+}$ ions in various molecular events of osteogenesis. Strontium in a low concentration promotes the activity of osteoblasts and stimulates new bone formation. ${ }^{184}$ At the same time, it suppresses the differentiation of osteoclasts and reduces bone resorption. ${ }^{185}$ Based on these properties, strontium-containing ceramics have been used as a coating material for biomedical implants. Strontium-containing bioactive glass coatings, ${ }^{186}$ strontium oxide doped titanium oxide coatings, ${ }^{187}$ and strontium carbonate incorporated PCL electrospun fibers ${ }^{188}$ release strontium ions, thereby enhancing the osteogenic activity of the implants. Our group has developed strontium-eluting PCL nanofibrous mats by doping strontium carbonate into nanofibers. They demonstrated that doping improves the proliferation of mesenchymal stem cells in addition to enhanced osteogenic activity. ${ }^{189}$

Niobium pentoxide coating has been reported to facilitate the growth of the apatite layer when incubated in a concentrated solution of $\mathrm{Ca}$ and phosphate ions. Nanostructured niobium pentoxide coating on the $\mathrm{Mg}$ substrate prepared by the sol-gel method improved attachment, growth, and differentiation of osteoblasts. ${ }^{190}$ Improvement in the differentiation of mesenchymal stem cells was observed in the case of niobium oxide-doped glass-ceramics. ${ }^{191}$ In another study, niobium pentoxide-coated titanium implants exhibited improved bioactivity and corrosion resistance compared to uncoated ones. ${ }^{192}$

The antibacterial mechanism of magnesium oxide nanoparticles is unclear, but many researchers correlate it with ROS production, which alters the cellular components of bacteria resulting in cell death. ${ }^{193}$ Hickey et al. developed a magnesium oxide coating on PLA using electrophoretic deposition. Magnesium oxide coating showed improved antibacterial potential against both Gram-positive and Gram-negative bacteria. The coating also exhibited improved osteoblast attachment by activating integrins through the release of magnesium ions and increased hydrophilicity after coating. They also showed that the fast degrading characteristics of magnesium nanoparticles could be used to tailor the mechanical properties of an implant over time. ${ }^{194}$

\subsection{Doped ceramics}

The application of a single-component ceramic coating may not be sufficient to meet different clinical needs, such as improving osseointegration, inhibiting bacterial infection, enhancing corrosion-wear resistance, and promoting angiogenesis. To address this wide variety of requirements, doping different elements in the ceramic coating offers a promising strategy. As mentioned above, it is a general practice to incorporate different elements into bioactive glass and CaP coatings to elicit additional biological responses. ${ }^{195}$ Similarly, several studies have reported the use of doped ceramic coatings on medical implants.

As discussed above, the release of $\mathrm{Zn}$ ions from $\mathrm{ZnO}$ particles ruptures bacterial membranes and induces leakage of intracellular components. Strontium has been known to promote bone formation, as discussed above. Deposition of a titanium oxide layer doped with $\mathrm{Zn}$ and strontium on the titanium surface by micro-arc oxidation was reported by Zhao et al. The study revealed that incorporating elements improved the antibacterial performance and osseointegration of the implant. ${ }^{196}$ Copperdoped titanium oxide coating demonstrated improved antibacterial, angiogenic, and osteogenic abilities compared to pure titanium oxide coating. ${ }^{197}$ Manganese dioxides exhibit antioxidant catalase mimicking activity, which is attributed to the presence of oxygen vacancies on the surface. Similar to cerium oxide, manganese oxide suppresses oxidative stress by controlling the ROS content. The doping of $\mathrm{Zn}$ into manganese dioxide helped in generating more oxygen vacancies with increased structural instability, inhibiting the manganese dioxide crystal growth and reducing its layer thickness. Consequently, the doped manganese oxide-coated titanium implant showed enhanced antioxidant catalase-like activity compared to undoped coating. The doped coating also demonstrated improved attachment, proliferation, and differentiation of osteoblasts due to increased hydrophilicity and release of $\mathrm{Mn}$ and $\mathrm{Zn}$ ions from the coating. ${ }^{198}$

Xu et al. developed a HA coating on the Mg AZ60 alloy by a chemical conversion method, imparting enhanced bioactivity and bio-integration. But owing to the porous nature of the HA coating, it cannot improve the corrosion resistance. This challenge was resolved by depositing another coating of copper oxidedoped titanium oxide with improved corrosion resistance. The layered coating showed good biocompatibility in addition to enhanced antibacterial activity. ${ }^{199}$ Thus, doped ceramic coatings impart better biological properties in comparison to undoped coating.

\section{Coating strategies}

Coating strategies play a pivotal role in maximizing the benefits of an implant by improving the physical performance and biocompatibility of the biomaterial. Several popular strategies of applying coating materials on biomedical implants have been reported in the literature, including dip-coating, electrophoretic deposition, plasma electrolyte oxidation/micro-arc oxidation, hydrothermal synthesis, plasma spraying, and magnetron 
sputtering, as depicted in Fig. 5. Some of the popular techniques are briefly summarized here.

\subsection{Dip coating}

Dip coating is a conventional chemical process to apply a coating on a biomedical implant. In this process, implants are dipped in a suspension of colloidal particles for an appropriate period of time. A wide range of ceramic coatings has been applied on implant surfaces with porous structures using this technique. Porous coatings provide an increased surface area for interaction with body fluids and to interact with the surrounding tissue. The process is technically simple and cost-effective in comparison to other coating techniques. $^{200} \mathrm{CaP}$ coatings are prepared by dip-coating using the two-layer method. The implant is first incubated in a solution of $\mathrm{Ca}$ ions, such as $\mathrm{CaCl}_{2}$ or $\mathrm{CaNO}_{3} \cdot 4 \mathrm{H}_{2} \mathrm{O}$, and subsequently dipped in a solution of phosphate ions, such as $\left(\mathrm{NH}_{4}\right)_{2} \mathrm{HPO}_{4}$ or $\mathrm{K}_{2} \mathrm{HPO}_{4} \cdot 3 \mathrm{H}_{2} \mathrm{O}$. Sometimes several dipping cycles are performed to achieve the desired thickness of the coating. ${ }^{201}$ Besides CaP coating, this technique can also be

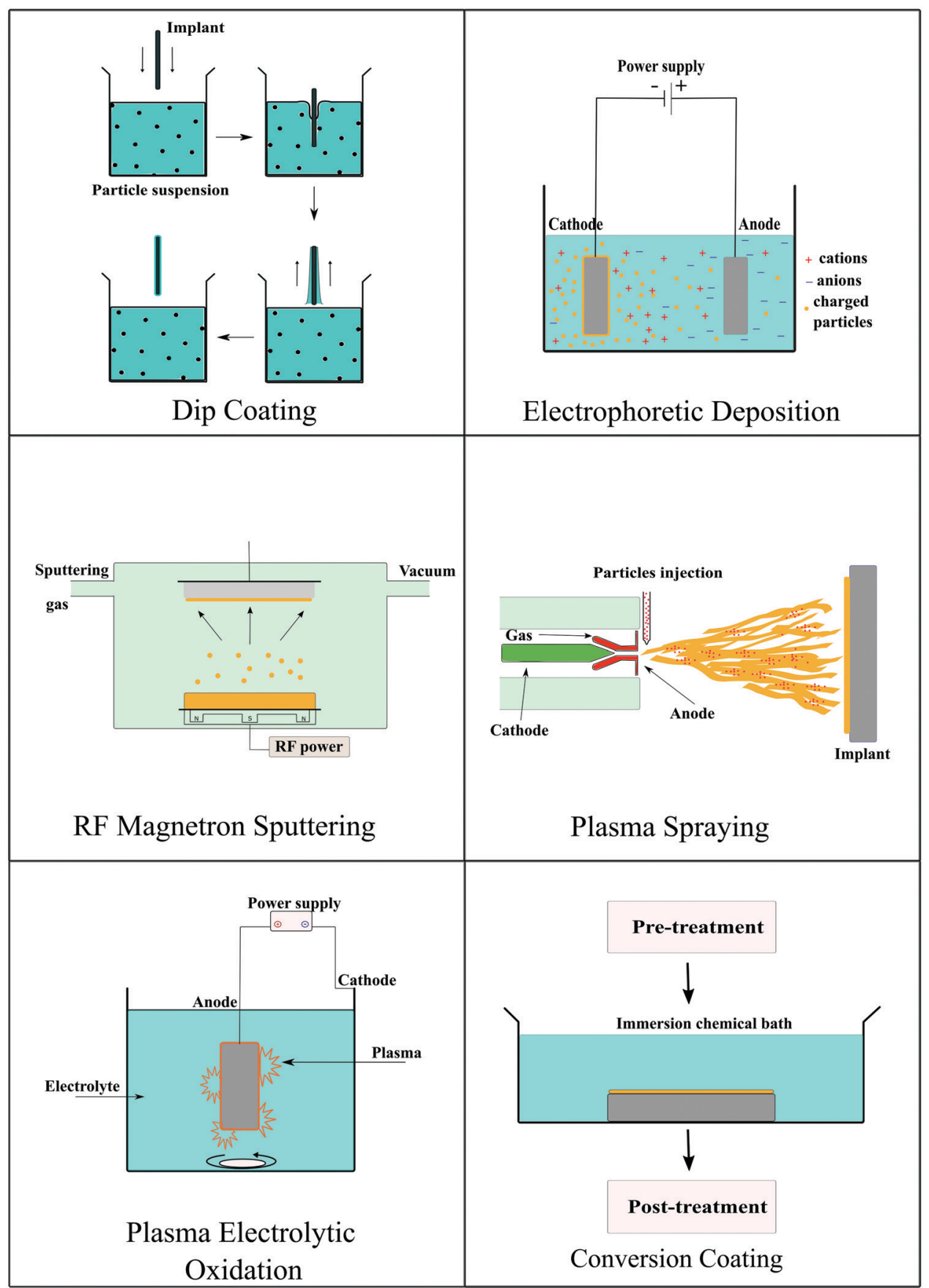

Fig. 5 Schematic summarizing the coating strategies utilized for preparing bioactive ceramic coatings on the surface of degradable implants. 
used to deposit titanium oxide, zirconia, and $\mathrm{ZnO}$ on $\mathrm{Mg}$ implants. ${ }^{202,203}$

\subsection{Electrophoretic deposition}

Electrophoretic deposition of coatings is based on the principle of electrophoresis. In electrophoresis, charged particles suspended in the solution migrate towards counter-charged electrodes under the influence of an electric field. The migrating particles accumulate at the oppositely charged electrode surface generating a uniform coating on the substrate. The solvent used in the process should have a suitable dielectric constant. The size of particles should be appropriate to remain stable in the colloidal state in the solvent. Hence, viscosity, conductivity, and zeta potential affect the thickness of the deposited film. ${ }^{204}$ Electrophoretic deposition is a simple, cheap, and rapid process that can deposit coatings on different substrates, even on complex shapes other than flat surfaces. Codeposition of different ceramic particles such as bioactive glass-HA, ${ }^{205}$ chitosan/alginate $\mathrm{HA},{ }^{206,207}$ and $\mathrm{ZnO}-\mathrm{HA}^{208}$ has also been achieved using this method. The coating of homogenous $\mathrm{ZnO}-$ HA on a silicone substrate was done by using the electrophoretic deposition method for improving the antibacterial activity. The silicone substrate was pretreated with oxygen plasma, and a thin titanium layer was deposited by DC sputtering. This thin titanium film-covered silicone was used as a substrate electrode in the deposition process. ${ }^{208}$ Many studies have reported the deposition of $\mathrm{HA}$ on $\mathrm{Mg}$ alloys using the electrophoretic deposition technique. ${ }^{209-211}$

\subsection{Radiofrequency magnetron sputtering}

Radiofrequency magnetron sputtering is a low-pressure technique used to deposit controlled and uniformly thick coatings on biomedical implants. In this method, the desired coating material prepared in the form of a target, is bombarded by reactive ions from gaseous plasma generating free atoms. Liberated atoms then travel through the vacuum and deposit on the substrate to form a uniform coating. The thickness, structure, and deposition rate of the coating depend upon deposition pressure and reactive gas flow rate along with the duration of the process. ${ }^{212}$ Cho et al. fabricated a PCL/HA 3D printed scaffold with $\mathrm{ZnO}$ coating by this method. They demonstrated that the deposited coating was uniform, and the thickness could be controlled by changing the duration of sputtering. ${ }^{67}$ Al-doped $\mathrm{ZnO}$ coating was fabricated on PLA films by magnetron sputtering. $\mathrm{ZnO} / \mathrm{Al}_{2} \mathrm{O}_{3}$ was used as a target to produce nanostructured coatings by varying the sputtering power. $^{213}$

\subsection{Plasma spraying}

Plasma spraying is the most commonly used thermal spraying method to create a coating on an implant surface. In this technique, an electric arc of high temperature and pressure is used to create a plasma jet. Fine particles of coating material are then injected into the jet to form molten particles. These molten particles are further deposited onto the substrate in the form of flattened drops to yield a coating on the implant. The plasma spray process has a high deposition rate, and the thickness, morphology, and structure of the coating can be tailored by modifying the deposition parameters. ${ }^{214}$ The plasma spray strategy has been used for coating metallic and polymeric implants. HA powder was plasma sprayed on a polyamide-carbon fiber surface using a plasma gun and argon gas. The coating was highly crystalline with good mechanical adhesion to the composite substrate. ${ }^{170}$

\subsection{Plasma electrolytic oxidation}

This method has been commonly used to deposit bioactive ceramic coatings on $\mathrm{Mg}$ and its alloys. It is also known as the micro-arc oxidation process. This process is carried out in an electrolytic bath, and $\mathrm{Mg}$ acts as the working electrode. This process is similar to anodization, but it uses a higher potential to generate plasma/micro-arc. The resulting micro-arc/plasma helps in developing a thick deposit layer. The coating formed by this method has a high bonding strength with the substrate, and the thick hard coating can impart hardness, corrosion, and wear resistance. The composition of the electrolytic bath, substrate composition, and process parameters affect the coating performance. ${ }^{215}$ Zirconia, $^{216}$ titanium oxide, ${ }^{89}$ and $\mathrm{CaP}^{217}$ based coatings are primarily deposited on $\mathrm{Mg}$ and its alloys using this technique.

\subsection{Conversion coating}

Conversion coating is a process of in situ formation of coating through chemical reactions between a substrate and a reaction additive. The nature of coating mainly depends upon the pre-treatment of the substrate and the type of treatment additive used. This process is very widely used for $\mathrm{Mg}$ and its alloys owing to their high reactivity. ${ }^{218}$ Magnesium fluoride and magnesium hydroxide-based conversion coatings are the most popular among all such coatings to improve the corrosion resistance of the substrate. The fluoride coating can stimulate osteoblast proliferation and increase mineral deposition. ${ }^{219}$ Cerium oxide $\mathrm{e}^{126,127}$ and phosphate ${ }^{220,221}$ based conversion coatings on $\mathrm{Mg}$ implants have also been reported in the literature.

Except for the strategies mentioned above, there are other methods to deposit a bioactive ceramic coating on the implant surface. However, the single coating technique does not offer the desired outcome. Hence, two or more deposition strategies are being used in more recent times, mainly for $\mathrm{Mg}$ and its alloys.

\section{Mechanical surface treatments}

Mechanical surface treatments have been applied successfully to significantly improve the biomechanical performance and cellular response of several conventional metallic biomaterials, including stainless steels ${ }^{222}$ and titanium alloys. ${ }^{223,224}$ Severe plastic deformation is often found to induce nanocrystallization at the surface. ${ }^{225}$ In this section, we describe the recent advancements in applying surface mechanical treatment strategies, which have been deployed for degradable Mg-based biomaterials. 
These treatments provide benefits like corrosion resistance, tunable degradation, wear resistance, fatigue performance, surface hardness, and strength. Some of the extensively used surface mechanical treatment strategies and their effect on degradable implant properties are briefly summarized here. Fig. 6 compiles some of these strategies, such as shot peening, laser shock peening, ball burnishing, and sand blasting.

Shot peening (SP) is a cold surface work hardening process that introduces near-surface compressive residual stress into the material to prevent fatigue crack initiation and growth. For instance, Liu et al., ${ }^{28}$ Wagner et al., ${ }^{226}$ and Fouad et al. ${ }^{227}$ have applied SP on Mg-based alloys, e.g., Mg-10Gd-3Y, AZ31 and AZ80, and ZK60 alloys, and reported that the surface modifications with SP generated effective compressive stresses which shifted the fatigue crack nucleation site from the surface to subsurface regions, thus improving the overall fatigue strength and corrosion resistance. Mhaede et al. ${ }^{159}$ applied SP with ceramic shots $(\mathrm{Z} 850, \varnothing 850 \mu \mathrm{m})$ on the AZ31 magnesium alloy followed by the electrodeposition of a calcium phosphate coating, e.g., DCPD. The SP + DCPD coated sample enabled better coating adhesion and exhibited a higher corrosion resistance as compared to the ground + DCPD coated sample. This clearly indicates the impact of SP in combination with the coating in controlling the corrosion resistance of Mg-based alloys.

Ball burnishing as a controlled process is shown to increase the corrosion resistance and mechanical surface integrity of Mg-based alloys. ${ }^{30,228}$ Salahshoor and Guo ${ }^{27,229}$ studied the process mechanics of ball burnishing and low plasticity burnishing and investigated the effect of different process parameters on improving the corrosion resistance and the mechanical surface integrity of $\mathrm{Mg}-\mathrm{Ca}$ alloys. Unlike low plasticity burnishing, severe plasticity burnishing integrated with cryogenic cooling has been employed to enhance the corrosion resistance of $\mathrm{Mg}-\mathrm{Al}-\mathrm{Zn}$ alloys, ${ }^{230}$ and the results were compared with the performance from the traditional grinding process. Cryogenic burnishing produced a fine-grained microstructure at a relatively larger depth, inducing severe compressive stress as well as generating a fine surface finish. Hydrogen evolution tests in $\mathrm{NaCl}$ solutions suggested that cryogenic burnishing reduced the corrosion rate by almost $50 \%$ as compared to the ground-only sample. Recently, Uddin et al. ${ }^{231}$ reported a synergistic approach combining burnishing and HA coating on AZ31B alloys, demonstrating that burnishing increased the surface activation energy enabling the growth of HA coating, and as a result, the corrosion resistance of the burnished + HA

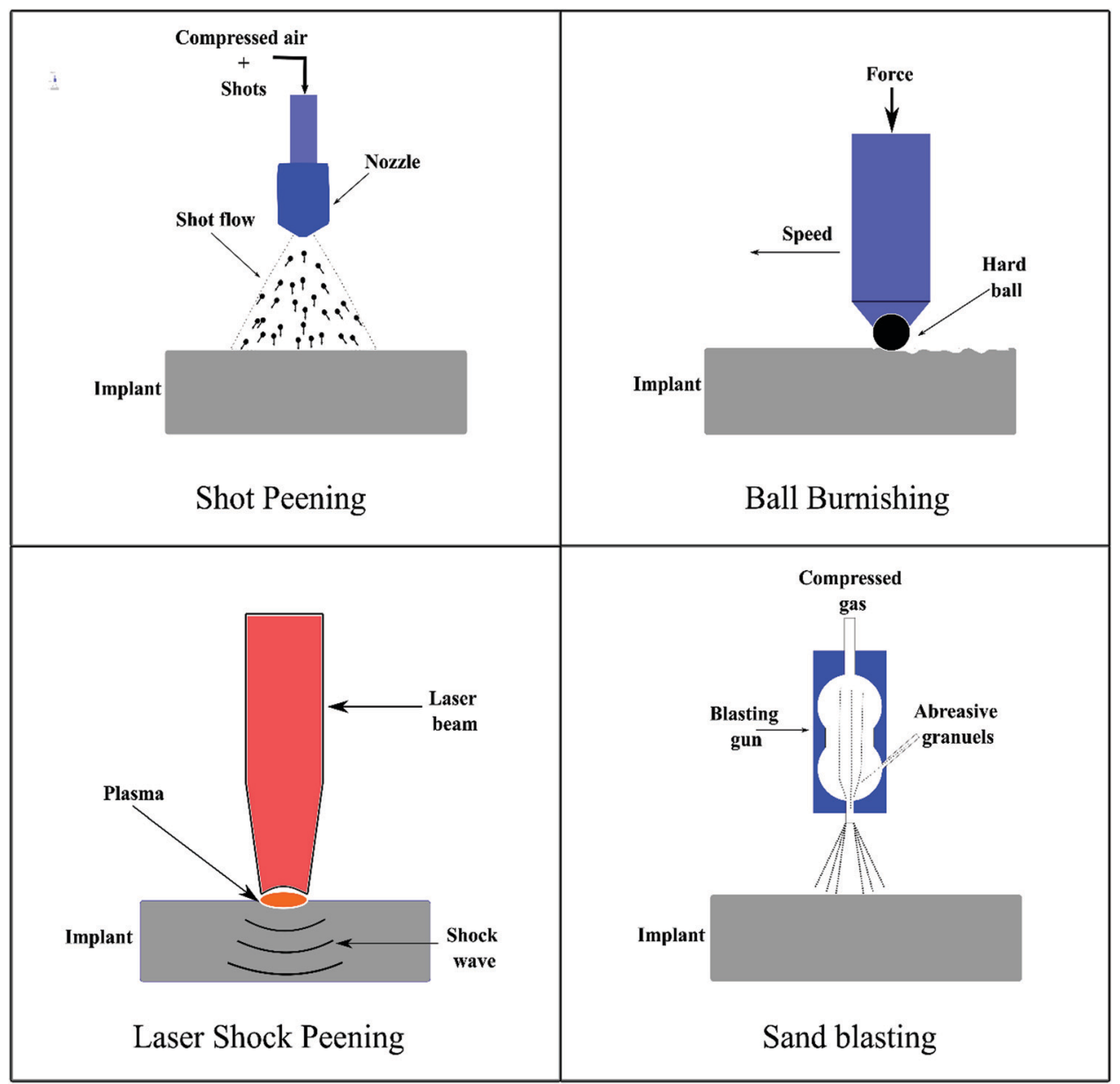

Fig. 6 Schematic summarizing the various surface mechanical treatments deployed to modify the surface of degradable implants. 
sample increased significantly without showing any negative response to immune cells as presented in Fig. 7 .

Sealy et al. ${ }^{232}$ used the laser shock peening (LSP) method to impart compressive residual stress to the $\mathrm{Mg}-\mathrm{Ca}$ alloy and found that high compressive residual stress has great potential to slow down the corrosion rates. Zhang et al. ${ }^{29}$ applied LSP on AZ31B Mg alloys and demonstrated that LSP not only improves the hardness, strength, wear, and fatigue performance but also significantly increases the corrosion resistance by releasing less amount of $\mathrm{Mg}$ ions and $\mathrm{H}_{2}$ gas as by-products. Recently,
Liu et $a .^{233}$ showed that LSP pre-treated AZ31B Mg alloys enabled more formation and adhesion of phosphate conversion coating, which eventually increased the corrosion resistance of the alloy. Similar results were reported for ZK60 $\mathrm{Mg}$ alloys with a $50 \%$ increase in corrosion resistance when modified by LSP compared to the untreated sample. ${ }^{234}$

Von der Höh et al. ${ }^{235}$ employed turning, cylinder threading, and sandblasting on $\mathrm{Mg}-0.8 \mathrm{Ca}$ alloy implants and investigated their effect on the in vivo degradation behavior of the alloy for a 3-6 month period. It was shown that turned and threaded ones (a)

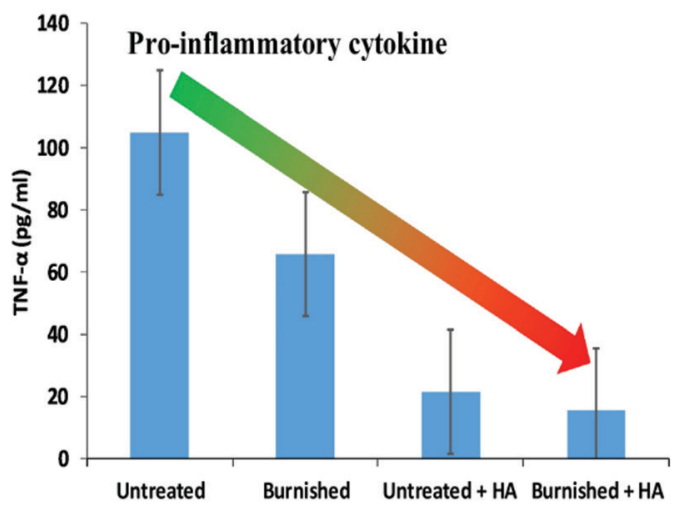

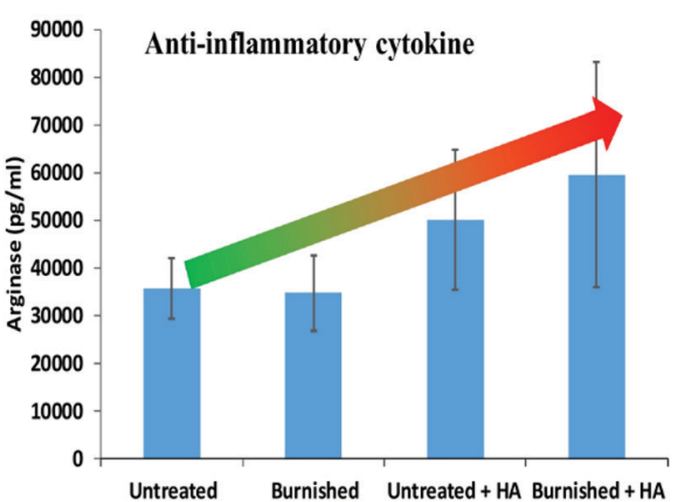

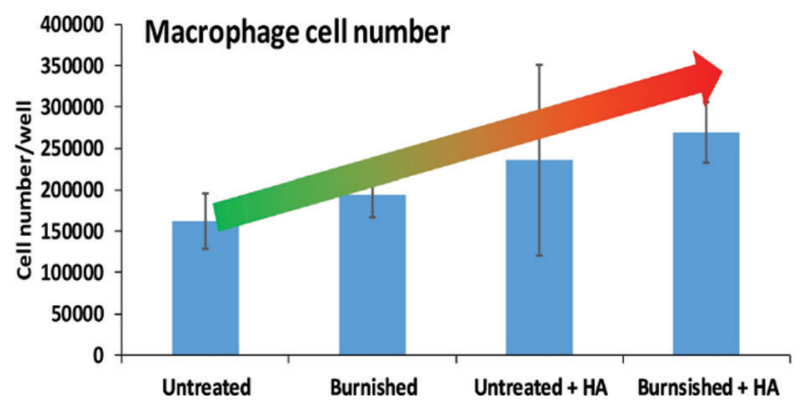

(b)

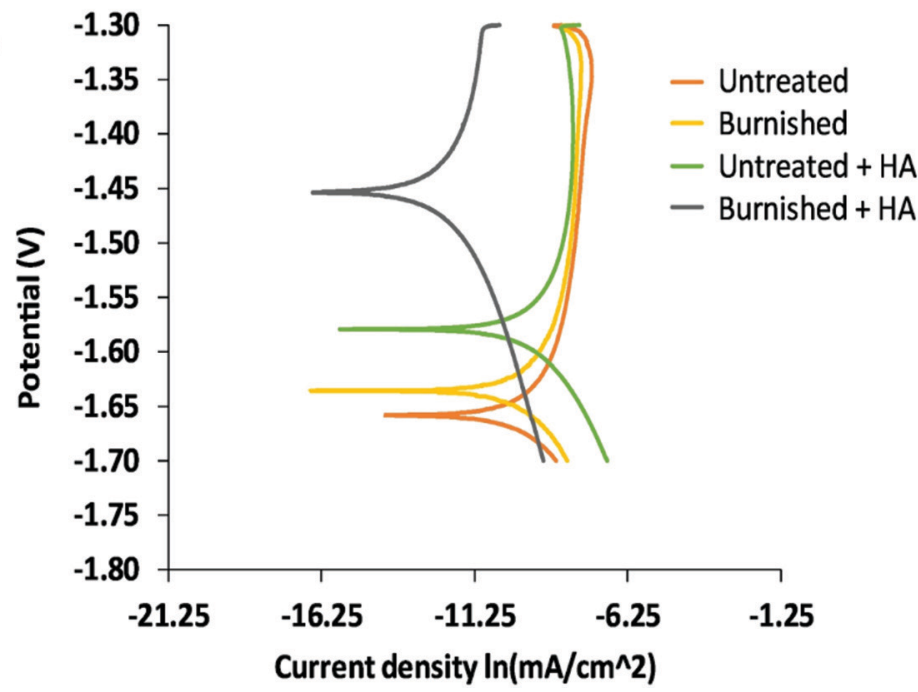

Fig. 7 (a) Immune cell response to various conditions such as untreated, burnished, and electrodeposited HA on the untreated and burnished surface and (b) potentiodynamic polarization curves of different samples [Reprinted with permission from ref. 231. Copyright 2021 Elsevier]. 
have higher corrosion resistance than the sanded sample. In addition, after 3 months, the turned implants showed the best bone-implant integration as compared to sandblasted and thread surfaces. Using turning, Denkena and Lucas ${ }^{236}$ attempted to control the degradation rate of $\mathrm{Mg}-3.0 \mathrm{Ca}$ alloys via modifying the surface integrity, including surface roughness and residual stress. It was reported that higher cutting forces due to a low cutting speed induced higher and deeper compressive stress and hence decreased the corrosion rate, while a fine surface finish under the same conditions was observed to have a negligible impact.

\section{Conclusion and future directions}

The surface of a biomaterial plays a crucial role in determining the performance of the medical device as several physical and chemical events are associated with the surface. The surface characteristics drive the biological response to the biomaterial. Modifying the surface of the biomaterial with a bioactive coating, mechanical treatment, or even their combination can have profound effects on the success of the implant as they provide enhanced biocompatibility in vivo along with other biomechanical and electrochemical benefits. The bioactive ceramic-coated degradable implant gives synergistic properties of both the coating and implants. Some bioactive ceramics such as bioactive glass, titanium oxide, and calcium phosphatebased ceramics are well studied, and their application as a coating for implants is now well established in the scientific literature. However, even as some other ceramics have the ability to impart specific responses to implants, their utility has not yet been extensively analyzed. At the same time, surface mechanical treatment is a promising method to improve the bio-corrosion potential along with enhanced fatigue resistance and ultimate tensile strength without compromising biocompatibility. A few studies have successfully combined mechanical treatments with bioactive ceramic coating to demonstrate the synergistic effects. In this review, we compiled and critically described several bioactive ceramics that have been applied as coatings to modulate the performance of implants focusing on resorbable biomaterials. Some of the common deposition methodologies used to coat implant surfaces were also described. Furthermore, several surface mechanical processes used for Mg-based degradable alloys and their effects on the alloy properties were discussed in this review.

Most of the bioactive coatings and surface mechanical treatments are reported for modification of non-degradable biomaterials. It is well known that degradable implants offer several benefits over conventional non-degradable devices, and thus, studies on surface modifications of degradable implants are essential and need more attention in the future. Another challenge in this field is the need for developing coating methods for uniformly coating porous foams or 3D printed scaffolds. Several of the widely employed coating strategies that are optimal for flat substrates are not suitable for porous implants. Similarly, the main limitation of mechanical surface treatments is that it is often difficult to modify the implant components with complex geometric shapes. Also, excessive cold working via these processes may damage the surface texture and geometric and dimensional accuracy, resulting in a detrimental effect on surface integrity. Design of appropriate process parameters in relation to the type of degradable materials being treated is crucial to achieve the desired performance in terms of degradation and mechanical integrity.

The kinetics and rate of degradation of the biomaterial can change after the application of a bioactive ceramic coating. It primarily depends on the nature, uniformity, and thickness of the coating material and the size, shape, and implantation site. A mismatch between the degradation rate of the implant and rate of tissue regeneration can cause implant failure. Thus, there is a need to develop predictive mathematical models and tools to characterize the degradation for minimizing failures. In addition to the degradation rate, strategies to enhance the adhesion between the coating and the substrates also need to be addressed. Thus, the rapidly growing field of biodegradable implants can benefit immensely from the modification of the surface of degradable implants by the application of bioactive coatings or mechanical treatments, but the clinical success of such surface-modified implants will need sustained efforts to resolve several challenges in this field.

\section{Conflicts of interest}

There are no conflicts to declare.

\section{Acknowledgements}

Support from the Department of Science and Technology (DST), Government of India, (DST/NM/NB/2018/119(G)) is gratefully acknowledged.

\section{References}

1 C. W. Kang and F. Z. Fang, Adv. Manuf., 2018, 6, 20-40.

2 R. Oriňaková, R. Gorejová, Z. Orságová Králová and A. Oriňak, Coatings, 2020, 10, 819.

3 B. Sultankulov, D. Berillo, K. Sultankulova, T. Tokay and A. J. B. Saparov, Biomolecules, 2019, 9, 470.

4 F. Croisier and C. Jérôme, Eur. Polym. J., 2013, 49, 780-792.

5 R. Parenteau-Bareil, R. Gauvin and F. J. M. Berthod, Materials, 2010, 3, 1863-1887.

6 T. P. Nguyen, Q. V. Nguyen, V.-H. Nguyen, T.-H. Le, V. Q. N. Huynh, D.-V. N. Vo, Q. T. Trinh, S. Y. Kim and Q. V. J. P. Le, Polymers, 2019, 11, 1933.

7 R. P. Pawar, S. U. Tekale, S. U. Shisodia, J. T. Totre and A. J. Domb, Recent Pat. Regener. Med., 2014, 4, 40-51.

8 G. Narayanan, V. N. Vernekar, E. L. Kuyinu and C. T. Laurencin, Adv. Drug Delivery Rev., 2016, 107, 247-276.

9 R. Kulkarni, K. Pani, C. Neuman and F. Leonard, Arch. Surg., 1966, 93, 839-843. 
10 D. Mondal, M. Griffith and S. S. Venkatraman, Int. J. Polym. Mater. Polym. Biomater., 2016, 65, 255-265.

11 R. M. Mohamed and K. Yusoh, Adv. Mater. Res., 2016, 1134, 249-255.

12 A. Basu and A. J. Domb, Adv. Mater., 2018, 30, 1706815.

13 J. Heller, B. Fritzinger, S. Ng and D. Penhale, J. Controlled Release, 1985, 1, 225-232.

14 Y. Chen, Z. Xu, C. Smith and J. Sankar, Acta Biomater., 2014, 10, 4561-4573.

15 S. Kamrani and C. Fleck, Biometals, 2019, 32, 185-193.

16 I. Pospíšilová and D. Vojtěch, Mater. Sci. Forum, 2014, 782, 457-460.

17 G. Katarivas Levy, J. Goldman and E. Aghion, Metals, 2017, 7, 402 .

18 M. Schinhammer, A. C. Hänzi, J. F. Löffler and P. J. Uggowitzer, Acta Biomater., 2010, 6, 1705-1713.

19 J. R. Jones, Acta Biomater., 2013, 9, 4457-4486.

20 N. Eliaz and N. Metoki, Materials, 2017, 10, 334.

21 C. G. Ambrose and T. O. Clanton, Ann. Biomed. Eng., 2004, 32, 171-177.

22 M. Prakasam, J. Locs, K. Salma-Ancane, D. Loca, A. Largeteau and L. Berzina-Cimdina, J. Funct. Biomater., 2017, 8, 44.

23 G. Hofmann, Arch. Orthop. Trauma Surg., 1995, 114, 123-132.

24 R. Narayanan, S. Seshadri, T. Kwon and K. Kim, J. Biomed. Mater. Res., Part B, 2008, 85, 279-299.

25 J. S. Fernandes, P. Gentile, R. A. Pires, R. L. Reis and P. V. Hatton, Acta Biomater., 2017, 59, 2-11.

26 A. A. Gorustovich, J. A. Roether and A. R. Boccaccini, Tissue Eng., Part B, 2010, 16, 199-207.

27 M. Salahshoor and Y. Guo, Int. J. Adv. Manuf. Technol., 2013, 64, 133-144.

28 W. Liu, J. Dong, P. Zhang, A. Korsunsky, X. Song and W. Ding, Mater. Sci. Eng., A, 2011, 528, 5935-5944.

29 R. Zhang, X. Zhou, H. Gao, S. Mankoci, Y. Liu, X. Sang, H. Qin, X. Hou, Z. Ren and G. L. Doll, Surf. Coat. Technol., 2018, 339, 48-56.

30 M. Uddin, C. Hall and P. Murphy, Sci. Technol. Adv. Mater., 2015, 16, 053501.

31 C. Li, C. Guo, V. Fitzpatrick, A. Ibrahim, M. J. Zwierstra, P. Hanna, A. Lechtig, A. Nazarian, S. J. Lin and D. L. Kaplan, Nat. Rev. Mater., 2020, 5, 61-81.

32 M. Peuster, C. Hesse, T. Schloo, C. Fink, P. Beerbaum and C. von Schnakenburg, Biomaterials, 2006, 27, 4955-4962.

33 M. Ulum, A. Arafat, D. Noviana, A. Yusop, A. Nasution, M. A. Kadir and H. Hermawan, Mater. Sci. Eng., C, 2014, 36, 336-344.

34 M. Sikora-Jasinska, P. Chevallier, S. Turgeon, C. Paternoster, E. Mostaed, M. Vedani and D. Mantovani, RSC Adv., 2018, 8, 9627-9639.

35 B. Liu, Y. Zheng and L. Ruan, Mater. Lett., 2011, 65, 540-543.

36 H. Li, Y. Zheng and L. Qin, Prog. Nat. Sci.: Mater. Int., 2014, 24, 414-422.

37 M. Schinhammer, P. Steiger, F. Moszner, J. F. Löffler and P. J. Uggowitzer, Mater. Sci. Eng., C, 2013, 33, 1882-1893.

38 H. Hermawan, H. Alamdari, D. Mantovani and D. Dube, Powder Metall., 2008, 51, 38-45.
39 D.-T. Chou, D. Wells, D. Hong, B. Lee, H. Kuhn and P. N. Kumta, Acta Biomater., 2013, 9, 8593-8603.

40 M. Moravej, S. Amira, F. Prima, A. Rahem, M. Fiset and D. Mantovani, Mater. Sci. Eng., B, 2011, 176, 1812-1822.

41 J. Cheng and Y. Zheng, J. Biomed. Mater. Res., Part B, 2013, 101, 485-497.

42 Q. Feng, D. Zhang, C. Xin, X. Liu, W. Lin, W. Zhang, S. Chen and K. Sun, J. Mater. Sci.: Mater. Med., 2013, 24, 713-724.

43 F. Witte, Acta Biomater., 2010, 6, 1680-1692.

44 Y.-W. Song, D.-Y. Shan, R.-S. Chen and E.-H. Han, Surf. Eng., 2007, 23, 334-338.

45 P.-R. Cha, H.-S. Han, G.-F. Yang, Y.-C. Kim, K.-H. Hong, S.-C. Lee, J.-Y. Jung, J.-P. Ahn, Y.-Y. Kim and S.-Y. Cho, Sci. Rep., 2013, 3, 1-6.

46 K. F. Farraro, K. E. Kim, S. L. Woo, J. R. Flowers and M. B. McCullough, J. Biomech., 2014, 47, 1979-1986.

47 Z. Li, X. Gu, S. Lou and Y. Zheng, Biomaterials, 2008, 29, 1329-1344.

48 M. Behera, M. Rajput, S. Acharya, N. Nadammal, S. Suwas and K. Chatterjee, Biomed. Mater., 2021, 16, 044109.

49 S. Zhang, X. Zhang, C. Zhao, J. Li, Y. Song, C. Xie, H. Tao, Y. Zhang, Y. He and Y. Jiang, Acta Biomater., 2010, 6, 626-640.

50 R. Song, M. Murphy, C. Li, K. Ting, C. Soo and Z. Zheng, Drug Des., Dev. Ther., 2018, 12, 3117.

51 H. Fang, C. Wang, S. Zhou, Z. Zheng, T. Lu, G. Li, Y. Tian and T. Suga, Corros. Sci., 2020, 168, 108466.

52 H. Fang, C. Wang, S. Zhou, G. Li, Y. Tian and T. Suga, J. Magnesium Alloys, 2021, 9, 1578-1594.

53 M. Alizadeh-Osgouei, Y. Li and C. Wen, Bioact. Mater., 2019, 4, 22-36.

54 F. Haghighat and S. A. H. Ravandi, Fibers Polym., 2014, 15, 71-77.

55 S. I. Jeong, B.-S. Kim, S. W. Kang, J. H. Kwon, Y. M. Lee, S. H. Kim and Y. H. Kim, Biomaterials, 2004, 25, 5939-5946.

56 O. S. Manoukian, M. R. Arul, N. Sardashti, T. Stedman, R. James, S. Rudraiah and S. G. Kumbar, J. Appl. Polym. Sci., 2018, 135, 46068.

57 Q. Dasgupta, G. Madras and K. Chatterjee, Int. Mater. Rev., 2019, 64, 288-309.

58 S. Nilawar, Q. Dasgupta, G. Madras and K. Chatterjee, Emergent Mater., 2019, 2, 153-168.

59 J. Natarajan, S. Rattan, U. Singh, G. Madras and K. Chatterjee, Ind. Eng. Chem. Res., 2014, 53, 7891-7901.

60 A. Banerjee, K. Chatterjee and G. Madras, Mater. Sci. Technol., 2014, 30, 567-573.

61 J. Pasquet, Y. Chevalier, J. Pelletier, E. Couval, D. Bouvier and M.-A. Bolzinger, Colloids Surf., A, 2014, 457, 263-274.

62 Y. Li, Y. Yang, R. L. Yun'an Qing, X. Tang, D. Guo and Y. Qin, Int. J. Nanomed., 2020, 15, 6247.

63 K. S. Suh, Y. S. Lee, S. H. Seo, Y. S. Kim and E. M. Choi, Biol. Trace Elem. Res., 2013, 155, 287-294.

64 R. Zhang, X. Liu, Z. Xiong, Q. Huang, X. Yang, H. Yan, J. Ma, Q. Feng and Z. Shen, Artif. Cells, Nanomed., Biotechnol., 2018, 46, 1123-1130.

65 G. Bisht and S. Rayamajhi, Nanobiomedicine, 2016, 3, 3-9. 
66 P. Nagajyothi, S. J. Cha, I. J. Yang, T. Sreekanth, K. J. Kim and H. M. Shin, J. Photochem. Photobiol., B, 2015, 146, 10-17.

67 Y. S. Cho, H.-K. Kim, M.-S. Ghim, M. W. Hong, Y. Y. Kim and Y.-S. Cho, Polymers, 2020, 12, 2193.

68 C. Venkatesh, M. Laurenti, M. Bandeira, E. Lanzagorta, L. Lucherini, V. Cauda and D. M. Devine, Coatings, 2020, 10, 1002.

69 A. Kania, W. Pilarczyk and R. Babilas, Acta Phys. Pol., A, 2018, 133, 222-224.

70 H. R. Bakhsheshi-Rad, E. Hamzah, A. F. Ismail, M. Aziz, M. Kasiri-Asgarani, H. Ghayour, M. Razzaghi and Z. Hadisi, Mater. Corros., 2017, 68, 1228-1236.

71 H. M. Mousa, A. Abdal-Hay, M. Bartnikowski, I. M. Mohamed, A. S. Yasin, S. O. Ivanovski, C. H. Park and C. S. Kim, ACS Biomater. Sci. Eng., 2018, 4, 2169-2180.

72 H. R. Bakhsheshi-Rad, E. Hamzah, W. S. Ying, M. Razzaghi, S. Sharif, A. F. Ismail and F. Berto, Materials, 2021, 14, 1930.

73 Y. Guo, S. Jia, L. Qiao, Y. Su, R. Gu, G. Li and J. Lian, Colloids Surf., B, 2020, 194, 111186.

74 I. Clarke, M. Manaka, D. Green, P. Williams, G. Pezzotti, Y.-H. Kim, M. Ries, N. Sugano, L. Sedel and C. Delauney, J. Bone Jt. Surg., 2003, 85, 73-84.

75 A. Apratim, P. Eachempati, K. K. K. Salian, V. Singh, S. Chhabra and C. Shah, J. Int. Soc. Prev. Community Dent., 2015, 5, 147.

76 N. P. Thomas, N. Tran, P. A. Tran, J. L. Walters, J. D. Jarrell, R. A. Hayda and C. T. Born, J. Mater. Sci.: Mater. Med., 2014, 25, 347-354.

77 A. Śmieszek, J. Szydlarska, A. Mucha, M. Chrapiec and K. Marycz, J. Biomater. Appl., 2017, 32, 570-586.

78 A. Seweryn, A. Pielok, K. Lawniczak-Jablonska, R. Pietruszka, K. Marcinkowska, M. Sikora, B. S. Witkowski, M. Godlewski, K. Marycz and A. Smieszek, Int. J. Nanomed., 2020, 15, 1595.

79 M. R. Goudarzi, M. Bagherzadeh, M. Fazilati, F. Riahi, H. Salavati and S. S. Esfahani, IET Nanobiotechnol., 2019, 13, 449-455.

80 R. Karimian, M. G. Mehrabani, B. Mehramuz, K. Ganbarov, L. Ejlali, A. Tanomand, F. S. Kamounah, M. A. Rezaee, M. Yousefi and E. Sheykhsaran, Adv. Pharm. Bull., 2020, 10, 577.

81 K. Huang, X. Lin, C. Xie and T. M. Yue, Bull. Mater. Sci., 2013, 36, 99-105.

82 Q. Yang, W. Yuan, X. Liu, Y. Zheng, Z. Cui, X. Yang, H. Pan and S. Wu, Acta Biomater., 2017, 58, 515-526.

83 H. K. Tsou and P. Y. Hsieh, Appl. Titanium Dioxide, 2017, 103-122.

84 S. Feng, F. Zhang, S. Ahmed and Y. Liu, Coatings, 2019, 9, 525.

85 H. Matsuno, R. Matsuyama, A. Yamamoto and K. Tanaka, Polym. J., 2015, 47, 505-512.

86 W. Xia, C. Lindahl, J. Lausmaa and H. Engqvist, Adv. Biomimetics, 2011, 20, 429-452.

87 S. Hou, W. Yu, Z. Yang, Y. Li, L. Yang and S. Lang, Coatings, 2020, 10, 999.
88 V. Hernández-Montes, C. P. Betancur-Henao and J. F. Santa-Marín, Dyna, 2017, 84, 261-270.

89 L. White, Y. Koo, Y. Yun and J. Sankar, J. Nanomater., 2013, 2013, 319437.

90 H.-K. Tsou, M.-H. Chi, Y.-W. Hung, C.-J. Chung and J.-L. He, BioMed Res. Int., 2015, 2015, 328943.

91 N. Anicic, M. Vukomanovic and D. Suvorov, RSC Adv., 2017, 7, 38647-38658.

92 P. R. P. Suma, R. V. Nair, W. Paul and R. S. Jayasree, Mater. Lett., 2020, 269, 127673.

93 A. Menazea, M. H. El-Newehy, B. M. Thamer and M. E. ElNaggar, J. Mol. Struct., 2021, 1225, 129163.

94 S. R. S. R. Kachupalli, M. V. Prasanth, K. N. Murthy, G. Subbaih, H. Janarthanam, S. K. Jayapalan and M. Sangeetha, AIP Conf. Proc., 2020, 2311, 080002.

95 Z. Wang, Y. Ma and Y. Wang, Metals, 2020, 10, 1146.

96 S. Meghana, P. Kabra, S. Chakraborty and N. Padmavathy, RSC Adv., 2015, 5, 12293-12299.

97 A. Muñoz-Escobar, Á. D. J. Ruíz-Baltazar and S. Y. ReyesLópez, Dose-Response, 2019, 17, 1559325819869502.

98 A. Muñoz-Escobar and S. Y. Reyes-López, PLoS One, 2020, 15, e0228864.

99 J. Balcucho, D. M. Narváez and J. L. Castro-Mayorga, Nanomaterials, 2020, 10, 1692.

100 A. Badaraev, A. Nemoykina, E. N. Bolbasov and S. I. Tverdokhlebov, Resour.-Effic. Technol., 2017, 3, 204-211.

101 H. Xie and Y. J. Kang, Curr. Med. Chem., 2009, 16, 1304-1314.

102 C. Stähli, M. James-Bhasin, A. Hoppe, A. R. Boccaccini and S. N. Nazhat, Acta Biomater., 2015, 19, 15-22.

103 L. R. Rivera, A. Cochis, S. Biser, E. Canciani, S. Ferraris, L. Rimondini and A. R. Boccaccini, Bioact. Mater., 2021, 6, 1479-1490.

104 Z. Lin, Y. Cao, J. Zou, F. Zhu, Y. Gao, X. Zheng, H. Wang, T. Zhang and T. Wu, Mater. Sci. Eng., C, 2020, 114, 111032.

105 L. Jaidev, S. Kumar and K. Chatterjee, Colloids Surf., B, 2017, 159, 293-302.

106 M. Arakha, S. Pal, D. Samantarrai, T. K. Panigrahi, B. C. Mallick, K. Pramanik, B. Mallick and S. Jha, Sci. Rep., 2015, 5, 1-12.

107 S. Pal, Antibacterial properties of iron oxide nanoparticles, MS thesis, NIT, Rourkela, 2014.

108 P. Mohan and R. Mala, Mater. Res. Express, 2019, 6, 115077. 109 P. Nehra, R. Chauhan, N. Garg and K. Verma, Br. J. Biomed. Sci., 2018, 75, 13-18.

110 M. Thukkaram, S. Sitaram and G. Subbiahdoss, Int. J. Biomater., 2014, 2014, 716080.

111 S. A. Rovers, R. Hoogenboom, M. F. Kemmere and J. T. Keurentjes, Soft Matter, 2012, 8, 1623-1627.

112 C. Xu, O. U. Akakuru, J. Zheng and A. Wu, Front. Bioeng. Biotechnol., 2019, 7, 141.

113 T.-J. Yu, P.-H. Li, T.-W. Tseng and Y.-C. Chen, Nanomedicine, 2011, 6, 1353-1363.

114 T. Suzuki, I. Kosacki, H. U. Anderson and P. Colomban, J. Am. Ceram. Soc., 2001, 84, 2007-2014.

115 Z. Hu, S. Haneklaus, G. Sparovek and E. Schnug, Commun. Soil Sci. Plant Anal., 2006, 37, 1381-1420. 
116 R. Di Monte and J. Kašpar, J. Mater. Chem., 2005, 15, 633-648.

117 C. Laberty-Robert, J. W. Long, K. A. Pettigrew, R. M. Stroud and D. R. Rolison, Adv. Mater., 2007, 19, 1734-1739.

118 F. R. Cassee, E. C. Van Balen, C. Singh, D. Green, H. Muijser, J. Weinstein and K. Dreher, Crit. Rev. Toxicol., 2011, 41, 213-229.

119 C. Korsvik, S. Patil, S. Seal and W. T. Self, Chem. Commun., 2007, 1056-1058.

120 I. A. P. Farias, C. C. L. d. Santos and F. C. Sampaio, BioMed Res. Int., 2018, 2018, 1923606.

121 I. A. Farias, C. C. Santos, A. L. Xavier, T. M. Batista, Y. M. Nascimento, J. M. Nunes, P. M. Silva, R. A. Menezes-Junior, J. M. Ferreira and E. O. Lima, Arabian J. Chem., 2021, 14, 102888.

122 S. Das, S. Singh, J. M. Dowding, S. Oommen, A. Kumar, T. X. Sayle, S. Saraf, C. R. Patra, N. E. Vlahakis and D. C. Sayle, Biomaterials, 2012, 33, 7746-7755.

123 R. Augustine, Y. B. Dalvi, P. Dan, N. George, D. Helle, R. Varghese, S. Thomas, P. Menu and N. Sandhyarani, ACS Biomater. Sci. Eng., 2018, 4, 4338-4353.

124 S. D. Purohit, H. Singh, R. Bhaskar, I. Yadav, C.-F. Chou, M. K. Gupta and N. C. Mishra, Mater. Sci. Eng., C, 2020, 116, 111111.

125 A. Jain, M. Behera, C. Mahapatra, N. R. Sundaresan and K. Chatterjee, Mater. Sci. Eng., C, 2021, 118, 111416.

126 A. P. Loperena, I. L. Lehr and S. B. Saidman, J. Magnesium Alloys, 2016, 4, 278-285.

127 L. Lingjie, L. Jinglei, Y. Shenghai, T. Yujing, Q. Jiang and P. Fusheng, J. Rare Earths, 2008, 26, 383-387.

128 X. Li, M. Qi, X. Sun, M. D. Weir, F. R. Tay, T. W. Oates, B. Dong, Y. Zhou, L. Wang and H. H. Xu, Acta Biomater., 2019, 94, 627-643.

129 C. Wu, L. Xia, P. Han, L. Mao, J. Wang, D. Zhai, B. Fang, J. Chang and Y. Xiao, ACS Appl. Mater. Interfaces, 2016, 8, 11342-11354.

130 M. Luo, M. Wang, W. Niu, M. Chen, W. Cheng, L. Zhang, C. Xie, Y. Wang, Y. Guo and T. Leng, Chem. Eng. J., 2021, 412, 128471.

131 H. Nosrati, R. A. Khouy, A. Nosrati, M. Khodaei, M. Banitalebi-Dehkordi, K. Ashrafi-Dehkordi, S. Sanami and Z. Alizadeh, J. Nanobiotechnol., 2021, 19, 1-21.

132 C. R. Patra, R. Bhattacharya, S. Patra, N. E. Vlahakis, A. Gabashvili, Y. Koltypin, A. Gedanken, P. Mukherjee and D. Mukhopadhyay, Adv. Mater., 2008, 20, 753-756.

133 R. Augustine, S. K. Nethi, N. Kalarikkal, S. Thomas and C. R. Patra, J. Mater. Chem. B, 2017, 5, 4660-4672.

134 L. L. Hench, J. Mater. Sci.: Mater. Med., 2006, 17, 967-978.

135 R. Sergi, D. Bellucci and V. Cannillo, Coatings, 2020, $10,757$.

136 A. Wren, A. Coughlan, P. Hassanzadeh and M. Towler, J. Mater. Sci.: Mater. Med., 2012, 23, 1331-1341.

137 A. S. Hameed, R. J. Al-Warid and I. A. Obaid, J. Univ. Babylon, 2016, 24, 1395-1400.

138 N. O. Joy-anne, Y. Su, X. Lu, P.-H. Kuo, J. Du and D. Zhu, Bioact. Mater., 2019, 4, 261-270.
139 N. Lakhkar, E. Abou Neel, V. Salih and J. Knowles, J. Mater. Sci.: Mater. Med., 2009, 20, 1339-1346.

140 M. O'donnell and R. Hill, Acta Biomater., 2010, 6, 2382-2385.

141 J. Blaker, S. Nazhat and A. Boccaccini, Biomaterials, 2004, 25, 1319-1329.

142 V. Yadav, M. Sankar and L. Pandey, J. Magnesium Alloys, 2020, 8, 999-1015.

143 J. Roether, A. R. Boccaccini, L. Hench, V. Maquet, S. Gautier and R. Jérôme, Biomaterials, 2002, 23, 3871-3878.

144 M. Zhu, L. Zhang, Q. He, J. Zhao, G. Limin and J. Shi, J. Mater. Chem., 2011, 21, 1064-1072.

145 S. Bansal, V. Chauhan, S. Sharma, R. Maheshwari, A. Juyal and S. Raghuvanshi, Indian J. Orthop., 2009, 43, 234.

146 Y. Shi, M. Qi, Y. Chen and P. J. M. L. Shi, Mater. Lett., 2011, 65, 2201-2204.

147 K. Chatterjee, L. Sun, L. C. Chow, M. F. Young and C. G. J. B. Simon Jr, Biomaterials, 2011, 32, 1361-1369.

148 X. Ge, Y. Leng, C. Bao, S. L. Xu, R. Wang and F. Ren, J. Biomed. Mater. Res., Part A, 2010, 95, 588-599.

149 M. Riaz, R. Zia, A. Ijaz, T. Hussain, M. Mohsin and A. Malik, Mater. Sci. Eng., C, 2018, 90, 308-313.

150 C. S. Ciobanu, S. L. Iconaru, M. C. Chifiriuc, A. Costescu, P. Le Coustumer and D. Predoi, BioMed Res. Int., 2013, 2013, 916218.

151 E. A. Ofudje, A. I. Adeogun, M. A. Idowu and S. O. Kareem, Heliyon, 2019, 5, e01716.

152 D. Predoi, S. L. Iconaru, M. V. Predoi, M. Motelica-Heino, R. Guegan and N. Buton, Nanomaterials, 2019, 9, 515.

153 O. Geuli, N. Metoki, T. Zada, M. Reches, N. Eliaz and D. Mandler, J. Mater. Chem. B, 2017, 5, 7819-7830.

154 M. Stigter, J. Bezemer, K. De Groot and P. Layrolle, J. Controlled Release, 2004, 99, 127-137.

155 S. B. Sulaiman, T. K. Keong, C. H. Cheng, A. B. Saim and R. B. H. Idrus, Indian J. Med. Res., 2013, 137, 1093.

156 S. Shadanbaz and G. J. Dias, Acta Biomater., 2012, 8, 20-30.

157 M. Rahman, Y. Li and C. Wen, J. Magnesium Alloys, 2020, 8, 929-943.

158 M. A. F. Zaludin, Z. A. Z. Jamal, S. B. Jamaludin and M. N. Derman, AIP Conf. Proc., 2016, 1756, 080001.

159 M. Mhaede, F. Pastorek and B. Hadzima, Mater. Sci. Eng., C, 2014, 39, 330-335.

160 C. Guo, X. Guo, N. Cai and Y. Dong, Mater. Lett., 2012, 74, 197-199.

161 H. Deplaine, M. Lebourg, P. Ripalda, A. Vidaurre, P. SanzRamos, G. Mora, F. Prósper, I. Ochoa, M. Doblaré and J. L. Gómez Ribelles, J. Biomed. Mater. Res., Part B, 2013, 101, 173-186.

162 J. Araujo, A. Martins, I. Leonor, E. D. Pinho, R. Reis and N. Neves, J. Biomater. Sci., Polym. Ed., 2008, 19, 1261-1278.

163 E. Prosecká, M. Buzgo, M. Rampichová, T. Kocourek, P. Kochová, L. Vysloužilová, D. Tvrdík, M. Jelínek, D. Lukáš and E. Amler, J. Biomed. Biotechnol., 2012, 2012, 428503.

164 M. Schneider, C. Günter and A. Taubert, Polymers, 2018, 10, 275. 
165 J. Jaroszewicz, J. Idaszek, E. Choinska, K. Szlazak, A. Hyc, A. Osiecka-Iwan, W. Swieszkowski and S. Moskalewski, Mater. Sci. Eng., C, 2019, 96, 319-328.

166 C. Choong, J. Triffitt and Z. Cui, Food Bioprod. Process., 2004, 82, 117-125.

167 W. Chen, L. Nichols, F. Brinkley, K. Bohna, W. Tian, M. W. Priddy and L. B. Priddy, Mater. Sci. Eng., C, 2021, 120, 111686.

168 L. Jaidev and K. Chatterjee, Mater. Des., 2019, 161, 44-54.

169 P. S. Poh, D. W. Hutmacher, B. M. Holzapfel, A. K. Solanki, M. M. Stevens and M. A. Woodruff, Acta Biomater., 2016, 30, 319-333.

170 C. Auclair-Daigle, M. Bureau, J. G. Legoux and L. H. Yahia, J. Biomed. Mater. Res., Part A, 2005, 73, 398-408.

171 S. Ahangarani, A. Sabour Rouhaghadam and M. Azadi, Int. J. Eng., 2016, 29, 677-687.

172 M. Brama, N. Rhodes, J. Hunt, A. Ricci, R. Teghil, S. Migliaccio, C. Della Rocca, S. Leccisotti, A. Lioi and M. Scandurra, Biomaterials, 2007, 28, 595-608.

173 S. P. Devaneyan, D. P. Pushpanathan, T. Senthilvelan and R. Ganesh, Mater. Today: Proc., 2018, 5, 11491-11497.

174 A. Vladescu, V. Pruna, S. Kulesza, V. Braic, I. Titorencu, M. Bramowicz, A. Gozdziejewska, A. Parau, C. M. Cotrut and I. Pana, Ceram. Int., 2019, 45, 1710-1723.

175 D. P. Pushpanathan, N. Alagumurthi and S. P. Devaneyan, Mater. Today: Proc., 2020, 22, 2565-2572.

176 C. Fares, S.-M. Hsu, M. Xian, X. Xia, F. Ren, J. J. Mecholsky, L. Gonzaga and J. Esquivel-Upshaw, Materials, 2020, 13, 3321.

177 M. Li, Y. Cheng, Y. Zheng, X. Zhang, T. Xi and S. Wei, Appl. Surf. Sci., 2012, 258, 3074-3081.

178 M. Tacikowski, M. Betiuk, K. Cymerman, M. Pisarek, I. Pokorska and T. Wierzchoń, J. Magnesium Alloys, 2014, 2, 265-273.

179 M. Tacikowski, J. Morgiel, M. Banaszek, K. Cymerman and T. Wierzchon, Trans. Nonferrous Met. Soc. China, 2014, 24, 2767-2775.

180 H. Altun and H. Sinici, Mater. Charact., 2008, 59, 266-270.

181 M. Annunziata, A. Oliva, M. A. Basile, M. Giordano, N. Mazzola, A. Rizzo, A. Lanza and L. Guida, J. Dent., 2011, 39, 720-728.

182 Y. S. A. Jabbari, J. Fehrman, A. C. Barnes, A. M. Zapf, S. Zinelis and D. W. Berzins, Coatings, 2012, 2, 160-178.

183 S. J. Gobbi, V. J. Gobbi, G. Reinke and Y. Rocha, Biomed. J. Sci. Tech. Res., 2019, 16, 1-3.

184 S. Takaoka, T. Yamaguchi, S. Yano, M. Yamauchi and T. Sugimoto, Horm. Metab. Res., 2010, 42, 627-631.

185 R. Baron and Y. Tsouderos, Eur. J. Pharmacol., 2002, 450, 11-17.

186 S. Kargozar, M. Montazerian, E. Fiume and F. Baino, Front. Bioeng. Biotechnol., 2019, 7, 161.

187 Z. Xu, H. Lu, J. Lu, C. Lv, X. Zhao and G. Wang, RSC Adv., 2018, 8, 3051-3060.

188 Q. Zhang, Y. Ji, W. Zheng, M. Yan, D. Wang, M. Li, J. Chen, X. Yan, Q. Zhang and X. Yuan, J. Nanomater., 2020, 2020, 1257646.
189 S. R. K. Meka, S. Jain and K. Chatterjee, Colloids Surf., B, 2016, 146, 649-656.

190 P. Amaravathy, S. Sowndarya, S. Sathyanarayanan and N. Rajendran, Surf. Coat. Technol., 2014, 244, 131-141.

191 J. H. Lopes, L. P. Souza, J. A. Domingues, F. V. Ferreira, M. de Alencar Hausen, J. A. Camilli, R. A. Martin, E. A. de Rezende Duek, I. O. Mazali and C. A. Bertran, J. Biomed. Mater. Res., Part B, 2020, 108, 1372-1387.

192 M. Mazur, M. Kalisz, D. Wojcieszak, M. Grobelny, P. Mazur, D. Kaczmarek and J. Domaradzki, Mater. Sci. Eng., C, 2015, 47, 211-221.

193 D. J. Hickey, D. Muthusamy and T. J. Webster, J. Biomed. Mater. Res., Part A, 2017, 105, 3136-3147.

194 D. J. Hickey, B. Ercan, L. Sun and T. J. Webster, Acta Biomater., 2015, 14, 175-184.

195 M. Šupová, Ceram. Int., 2015, 41, 9203-9231.

196 Q. Zhao, L. Yi, L. Jiang, Y. Ma, H. Lin and J. Dong, Nanomedicine, 2019, 16, 149-161.

197 Q. Wu, J. Li, W. Zhang, H. Qian, W. She, H. Pan, J. Wen, X. Zhang, X. Liu and X. Jiang, J. Mater. Chem. B, 2014, 2, 6738-6748.

198 S. Liu, K. Li, T. Hu, D. Shao, S. Huang, Y. Xie and X. Zheng, Colloids Surf., B, 2021, 202, 111666.

199 Y. Xu, T. Wang, Y. Guo, G. Li and J. Lian, Langmuir, 2020, 36, 13937-13948.

200 C. Brinker, A. Hurd, P. Schunk, G. Frye and C. Ashley, J. Non-Cryst. Solids, 1992, 147, 424-436.

201 K. Ishikawa and A. Kareiva, Chemija, 2020, 31, 25-41.

202 H. Hornberger, S. Virtanen and A. R. Boccaccini, Acta Biomater., 2012, 8, 2442-2455.

203 J. E. López Herrera, V. Hernández Montes, C. P. Betancur Henao, J. F. Santa Marín and R. Buitrago Sierra, INGE CUC, 2018, 14, 45-54.

204 A. R. Boccaccini, J. A. Roether, B. J. Thomas, M. S. Shaffer, E. Chavez, E. Stoll and E. J. Minay, J. Ceram. Soc. Jpn., 2006, 114, 1-14.

205 D. Zhitomirsky, J. Roether, A. Boccaccini and I. Zhitomirsky, J. Mater. Process. Technol., 2009, 209, 1853-1860.

206 M. Đošić, S. Eraković, A. Janković, M. Vukašinović-Sekulić, I. Z. Matić, J. Stojanović, K. Y. Rhee, V. Mišković-Stanković and S.-J. Park, J. Ind. Eng. Chem., 2017, 47, 336-347.

207 X. Pang and I. Zhitomirsky, Int. J. Nanosci., 2005, 4, 409-418.

208 T. G. P. Galindo, T. Kataoka, S. Fujii, M. Okuda and M. Tagaya, Colloid Interface Sci. Commun., 2016, 10, 15-19.

209 R. M. Kumar, K. K. Kuntal, S. Singh, P. Gupta, B. Bhushan, P. Gopinath and D. Lahiri, Surf. Coat. Technol., 2016, 287, 82-92.

210 S. Kaabi Falahieh Asl, S. Nemeth and M. J. T. Tan, Prog. Cryst. Growth Charact. Mater., 2013, 60, 3-4.

211 A. Saadati, H. Hesarikia, M. R. Nourani and R. A. Taheri, Surf. Eng., 2020, 36, 908-918.

212 P. J. Kelly and R. D. Arnell, Vacuum, 2000, 56, 159-172.

213 D. Valerini, L. Tammaro, F. Di Benedetto, L. Capodieci, R. Terzi and A. Rizzo, Workshop on Nanotechnology in 
Instrumentation and Measurement (NANOFIM), 2015, 2015, 17990442.

214 M. F. Smith, A. C. Hall, J. D. Fleetwood and P. Meyer, Coatings, 2011, 1, 117-132.

215 G. B. Darband, M. Aliofkhazraei, P. Hamghalam and N. Valizade, J. Magnesium Alloys, 2017, 5, 74-132.

216 P. B. Srinivasan, J. Liang, C. Blawert and W. Dietzel, Appl. Surf. Sci., 2010, 256, 3265-3273.

217 B. Wang, J. Gao, L. Wang, S. Zhu and S. Guan, Mater. Lett., 2012, 70, 174-176.

218 X. Chen, N. Birbilis and T. Abbott, Corrosion, 2011, 67, 035005.

219 M. Uddin, C. Hall and P. Murphy, Sci. Technol. Adv. Mater., 2015, 16, 053501.

220 X.-B. Chen, H.-Y. Yang, T. B. Abbott, M. A. Easton and N. Birbilis, Surf. Eng., 2014, 30, 871-879.

221 R. Zeng, Z. Lan, L. Kong, Y. Huang and H. Cui, Surf. Coat. Technol., 2011, 205, 3347-3355.

222 S. Bahl, P. Shreyas, M. Trishul, S. Suwas and K. Chatterjee, Nanoscale, 2015, 7, 7704-7716.

223 S. Bahl, S. R. K. Meka, S. Suwas and K. Chatterjee, ACS Biomater. Sci. Eng., 2018, 4, 3132-3142.

224 S. Acharya, A. G. Panicker, V. Gopal, S. S. Dabas, G. Manivasagam, S. Suwas and K. Chatterjee, Mater. Sci. Eng., C, 2020, 110, 110729.
225 S. Acharya, S. Suwas and K. Chatterjee, Nanoscale, 2021, 13, 2286-2301.

226 L. Wagner, M. Hilpert, J. Wendt and B. Küster, Mater. Sci. Forum, 2003, 419, 93-102.

227 Y. Fouad, M. Mhaede and L. Wagner, Fatigue Fract. Eng. Mater. Struct., 2011, 34, 403-407.

228 M. S. Uddin, C. Hall, R. Hooper, E. Charrault, P. Murphy and V. Santos, Metals, 2018, 8, 136.

229 M. Salahshoor and Y. Guo, Procedia CIRP, 2014, 13, 143-149.

230 Z. Pu, J. Outeiro, A. Batista, O. Dillon Jr, D. Puleo and I. Jawahir, Int. J. Mach. Tools Manuf., 2012, 56, 17-27.

231 M. Uddin, C. Hall, V. Santos, R. Visalakshan, G. Qian and K. Vasilev, Mater. Sci. Eng., C, 2021, 118, 111459.

232 M. Sealy and Y. Guo, J. Mech. Behav. Biomed. Mater., 2010, 3, 488-496.

233 H. Liu, Z. Tong, W. Zhou, Y. Yang, J. Jiao and X. Ren, J. Alloys Compd., 2020, 846, 155837.

234 Y. Guo, S. Wang, W. Liu, T. Xiao, G. Zhu and Z. Sun, Metals, 2019, 9, 1237.

235 N. Von der Höh, B. Von Rechenberg, D. Bormann, A. Lucas and A. Meyer-Lindenberg, Materials science and technology: development, production, testing, properties and applications of technical materials, 2009, vol. 40, pp. 88-93.

236 B. Denkena and A. Lucas, CIRP Ann., 2007, 56, 113-116. 